Check for updates

Cite this: Chem. Sci., 2018, 9, 1408

Received 8th December 2017

Accepted 5th January 2018

DOI: $10.1039 / \mathrm{c} 7 \mathrm{sc} 05210 \mathrm{c}$

rsc.li/chemical-science

\section{Porphyrinoids as a platform of stable radicals}

\author{
Daiki Shimizu (D) and Atsuhiro Osuka (DD*
}

The non-innocent ligand nature of porphyrins was observed for compound I in enzymatic cycles of cytochrome P450. Such porphyrin radicals were first regarded as reactive intermediates in catabolism, but recent studies have revealed that porphyrinoids, including porphyrins, ring-contracted porphyrins, and ring-expanded porphyrins, display excellent radical-stabilizing abilities to the extent that radicals can be handled like usual closed-shell organic molecules. This review surveys four types of stable porphyrinoid radical and covers their synthetic methods and properties such as excellent redox properties, NIR absorption, and magnetic properties. The radical-stabilizing abilities of porphyrinoids stem from their unique macrocyclic conjugated systems with high electronic and structural flexibilities.

\section{Introduction}

Porphyrins and related macrocycles ${ }^{1}$ play important roles in nature, as exemplified by the special pair of chlorophylls in the photosynthetic reaction center (RC), hemes, and cyanocobalamine (vitamin $\mathrm{B}_{12}$ ), to fulfill various biofunctions. Key features of these "pigments of life" are redox-active behaviors, coordination abilities, and light-harvesting properties. For example, the special pair of chlorophyll in the RC, upon photoexcitation, transfers an electron to an acceptor to form its radical cation, which triggers subsequent electron transfer events in photosynthesis known as the Z-scheme. ${ }^{2 a}$ Another example is cytochrome P450, which acts as a hydroxylation catalyst via the involvement of a radical cation intermediate (known as compound I; Fig. 1). ${ }^{2 b}$ Therefore, radicals and radical ions of porphyrins have been extensively investigated as models of intermediates in key biochemical processes. These radicals are usually short-lived and highly reactive. On the other hand, recent studies have

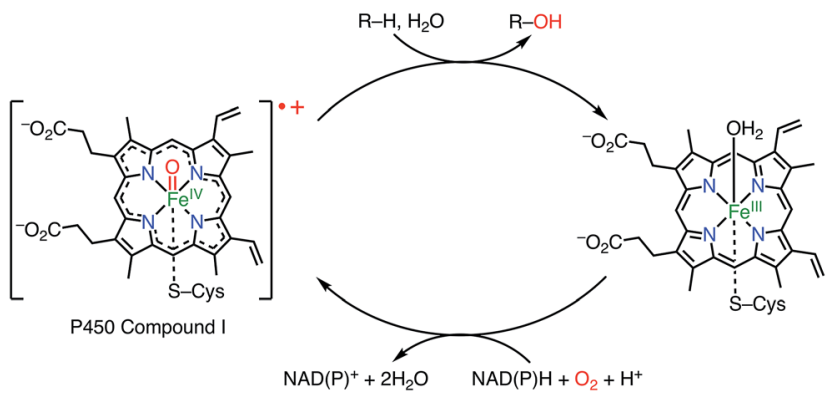

Fig. 1 Cytochrome P450 compound I.

Department of Chemistry, Graduate School of Science, Kyoto University, Kyoto 606-8502, Japan. E-mail: osuka@kuchem.kyoto-u.ac.jp revealed that some porphyrinoid radicals and radical ions are extremely stable.

Here, we review the exceptionally effective radical-stabilizing abilities of porphyrinoids, including porphyrins, ringcontracted porphyrins, ring-expanded porphyrins, and coremodified porphyrins. In early studies, radicals stabilized by porphyrinoids had been found serendipitously, but in recent studies it has been demonstrated that the installation of a porphyrinoid at an appropriate conjugative position can be a general strategy for producing a stable radical. Importantly, in most cases radicals have been stabilized by porphyrinoids to such an extent that they are tolerant of air, moisture, and silica gel column chromatography, so that they can be handled like usual organic molecules. In special cases, radicals can undergo chemical transformations for their further modification.

It has been shown that porphyrinoids, in particular expanded porphyrins, are a suitable platform for generating various electronic states such as Hückel and Möbius (anti) aromatic species. ${ }^{1 f-i}$ This ability has been attributed to their structural and electronic flexibilities. The structural flexibilities of expanded porphyrins allow facile conformational changes upon a change in the number of $\pi$-electrons. A representative example is hexaphyrin(1.1.1.1.1.1), which can exist as a planar $26 \pi$ Hückel aromatic species 1 and a twisted $28 \pi$ Möbius aromatic species 2, which are both stable compounds (Fig. 2). The electronic flexibilities of porphyrinoids are closely related to the facile amine-imine (pyrrole-pyrrolenine) interconversion of their pyrrole segments. For example, porphyrins consist of two amine-type and two imine-type pyrroles and can accommodate $16-20 \pi$ electronic states via changes in the amine or imine forms of the pyrroles. ${ }^{3}$ Because the amine-type pyrroles can act as electron donors and the imine-type pyrroles can act as electron acceptors, porphyrins are subject to both oxidation and reduction. The stabilities of the resulting non- or anti-aromatic electronic states should be correlated with the macrocyclic aromatic stabilization energy. ${ }^{4}$ The total aromatic stabilization 


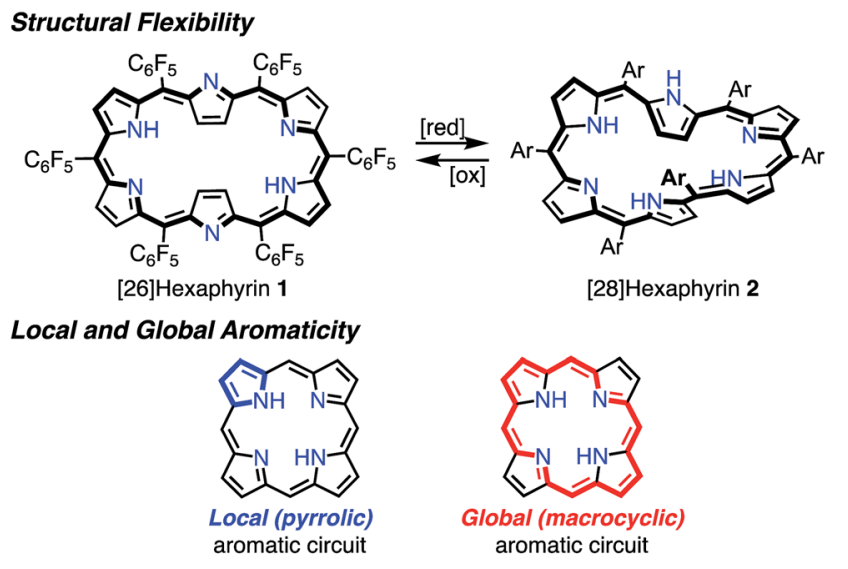

Amine-Imine Interconversion upon Oxidation/Reduction
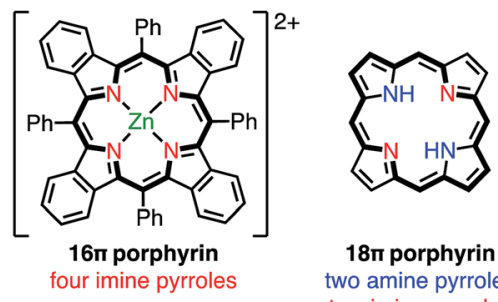

$18 \pi$ porphyrin two amine pyrroles two imine pyrroles

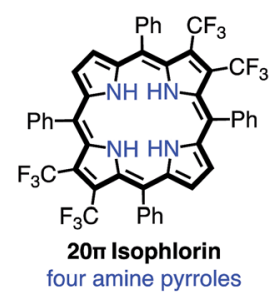

Fig. 2 Important ideas for understanding the structural and electronic properties of porphyrins.

energies of porphyrinoids largely depend on the local aromaticity of the constituent pyrroles. Thus, the contribution of the macrocyclic aromatic stabilization energy is relatively small. ${ }^{4 b}$ Although the macrocyclic aromaticity is energetically low, aromatic porphyrinoids display an effective macrocyclic conjugated network as evidenced by strong diatropic ring currents, which are predominantly due to the global conjugation circuit. A theoretical interpretation of this specific balance between aromaticity and conjugation has been attempted. ${ }^{4 a}$ It is considered that these unique electronic and structural flexibilities generally play important roles in stabilizing radicals as well as aromatic and anti-aromatic species.

Although there are many studies of porphyrinoids that are covalently linked to or coordinated with stable localized radicals (e.g. nitroxides and nitronyl nitroxides), ${ }^{5}$ this review will focus on organic radicals stabilized by spin delocalization over the $\pi$ electron systems of porphyrinoids.

\section{Classification of porphyrinoid- based radicals}

Porphyrinoid-based radicals can be classified into four types according to the origin of the radical, as shown in Fig. 3: (i) oneelectron-oxidized/reduced radical ions (Chapter 3), (ii) substituent-centered neutral radicals (Chapter 4), (iii) noninnocent macrocyclic radicals of metal complexes (Chapter 5), and (iv) Kekulé/non-Kekulé-type diradicals (Chapter 6). Regardless of this classification, stable organic radicals are required to satisfy the following criteria: (1) effective

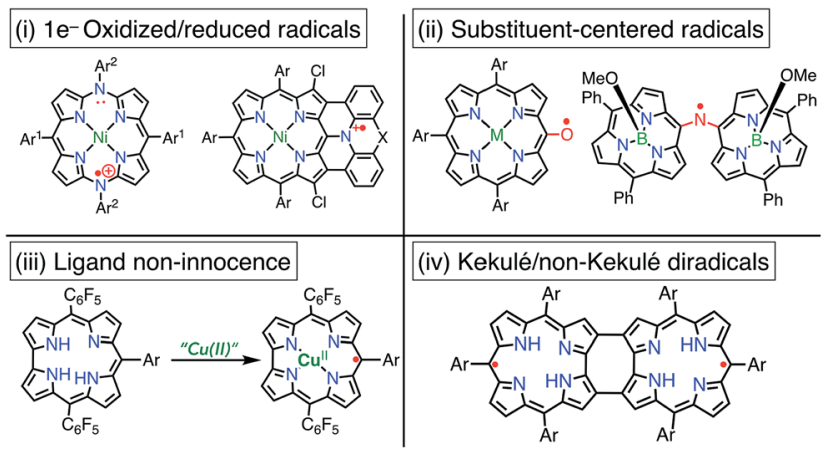

Fig. 3 Four types of porphyrinoid-based stable radicals.

delocalization of spin density for thermodynamic stabilization, (2) appropriate steric protection (kinetic stabilization) to avoid dimerization and undesired reactions, and (3) moderate redox potentials to prevent the facile reduction and oxidation of the radical itself. Therefore, most stable radicals are neutral species.

\subsection{Methodologies for characterization of porphyrinoid radicals}

Because porphyrinoid radicals have unique open-shell electronic structures, they should be characterized very carefully. For example, delocalized radicals are NMR-silent owing to fast electronic relaxations. Because NMR spectroscopy is not effective for radicals, the structural determination of radicals largely relies on X-ray diffraction analysis. When X-ray analysis is impossible, NMR characterizations of $1 \mathrm{e}^{-}$oxidized or reduced compounds are also useful. EPR spectra with hyperfine couplings sometimes provide structural information, but porphyrinoid radicals frequently display isotropic signals around $g=2$ without hyperfine structures. On the other hand, anisotropic EPR signals indicate the contribution of spin-orbit interactions with coordinated metals. Quantitative insights into spin states can be obtained by using VT-EPR, SQUID, and NMR studies. In the case of metalloporphyrinoids, the determination of the valence of the central metal is also important and is often provided by Mössbauer and X-ray photoelectron spectroscopies. The nature of the spin distribution can be estimated from hyperfine coupling constants in EPR spectra and via theoretical calculations.

\section{One-electron-oxidized/reduced radical ions}

Metalloporphyrins are easily oxidized or reduced to generate the corresponding radical cations or radical anions, which often occur not on the central metal but on the porphyrin macrocycle. ${ }^{6}$ These transformations can be accomplished by chemical reactions or electrochemical methods, but the radical ions thus generated are mostly reactive and thus unstable. ${ }^{7}$ However, in recent years, very stable porphyrinoid radical ions have been found. In this section, we discuss recent examples of stable radical ions of porphyrinoids. 


\subsection{Stable radical cations of porphyrinoids}

Diazaporphyrin is a macrocycle in which two methine-carbon of porphyrin are replaced by nitrogen atoms. Matano et al. reported multi-redox processes of the $20 \pi$ anti-aromatic 5,15diazaporphyrins $\mathbf{3} \mathbf{M}(\mathbf{M}=\mathrm{Ni}, \mathrm{Zn}, \mathrm{Cu}) .{ }^{8}$ Owing to their electronrich nature, $\mathbf{3} \mathbf{M}$ exhibited multiple stable oxidation states. For example, two-electron oxidation of $3 \mathbf{M}$ with $\mathrm{AgPF}_{6}$ afforded $16 \pi$ electron dications $\mathbf{3} \mathbf{M}\left(\mathbf{P F}_{\mathbf{6}}\right)_{2}$, and subsequent reduction with $\mathrm{NaBH}_{4}$ or $\mathrm{CoCp}_{2}$ gave $19 \pi$-electron monocations $3 \mathbf{M}\left(\mathbf{P F}_{\mathbf{6}}\right)$ as stable compounds (Fig. 4). The free-base derivative $\mathbf{3 H}_{\mathbf{2}}\left(\mathbf{P F}_{\mathbf{6}}\right)$ was also prepared via demetalation of the corresponding $\mathrm{Mg}$ (II) complex $3 \mathbf{M g}$ followed by chemical $1 \mathrm{e}^{-}$oxidation. These radical cations were fairly stable under ambient conditions and were purified by silica gel column chromatography. The redox potentials of $\mathbf{3 N i}\left(\mathbf{P F}_{\mathbf{6}}\right)$ were determined by cyclic voltammetry to be $E_{\mathrm{ox} 1}=0.29 \mathrm{~V}(20 \pi / 19 \pi)$ and $E_{\mathrm{red} 1}=-0.37 \mathrm{~V}(19 \pi / 18 \pi) v s . \mathrm{Ag} /$ $\mathrm{Ag}^{+}$in $\mathrm{CH}_{2} \mathrm{Cl}_{2}$. Importantly, the mixing of $3 \mathrm{Ni}$ and $3 \mathbf{N i}\left(\mathbf{P F}_{\mathbf{6}}\right)_{2}$ also afforded the radical cation $\mathbf{3 N i}\left(\mathbf{P F}_{\mathbf{6}}\right)$ as evidenced by the EPR spectrum, which exhibited hyperfine coupling with the two meso-nitrogen atoms and four $\beta$-protons. The absorption

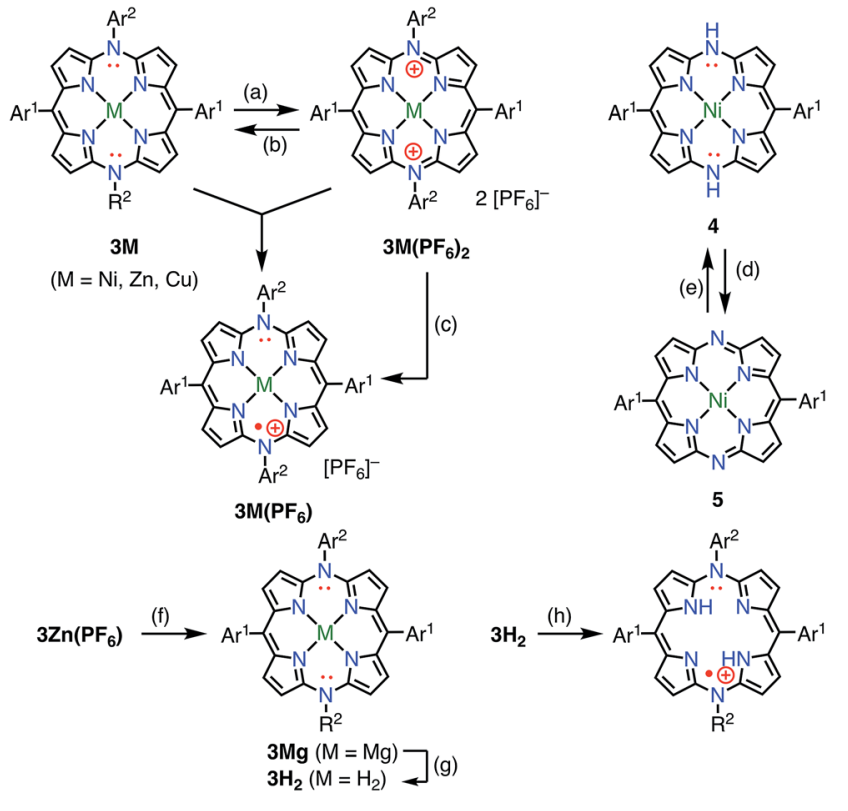

<Proposed catalytic cycle for the dimerization of $\mathrm{PhMgBr}$ catalyzed by $\mathbf{3} \mathrm{Mg}$ >

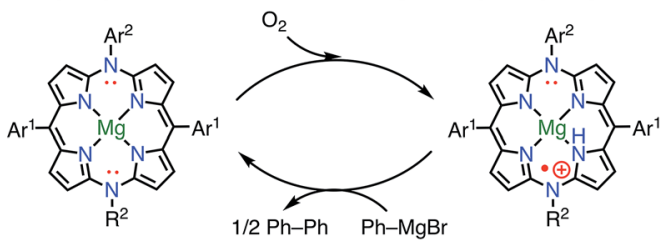

Fig. 4 Redox scheme of diazaporphyrins. (a) 2 equiv. $\mathrm{AgPF}_{6}, \mathrm{CH}_{2} \mathrm{Cl}_{2}$, rt, $2 \mathrm{~min}, 85 \%$ for $3 \mathrm{Ni}\left(\mathrm{PF}_{6}\right)_{2}, 82 \%$ for $3 \mathrm{Zn}\left(\mathrm{PF}_{6}\right)_{2}, 75 \%$ for $3 \mathrm{Cu}\left(\mathrm{PF}_{6}\right)_{2}$; (b) excess $\mathrm{NaBH}_{4}, \mathrm{THF}, \mathrm{rt}, 8 \mathrm{~h}, 77 \%$ for $3 \mathrm{Ni}\left(\mathrm{PF}_{6}\right)_{2}$; (c) 1 equiv. $\mathrm{NaBH}_{4}$ or $\mathrm{CoCp} 2, \mathrm{MeOH}, 2 \mathrm{~min}, 80 \%$ for $3 \mathrm{Ni}\left(\mathrm{PF}_{6}\right), 85 \%$ for $3 \mathrm{Zn}\left(\mathrm{PF}_{6}\right), 75 \%$ for $3 \mathrm{Cu}\left(\mathrm{PF}_{6}\right)$; (d) N, $\mathrm{N}^{\prime}$-bis(trimethylsilyl)-1,4-dihydropyrazine, THF, rt, $48 \mathrm{~h}$, then $\mathrm{MeOH}, 78 \%$; (e) aerobic oxidation; (f) 61 equiv. $\mathrm{PhMgBr}$, toluene/ THF, rt, $10 \mathrm{~min}$, not isolated; (g) trifluoroacetic acid, $70{ }^{\circ} \mathrm{C}, 7 \mathrm{~h}, 38 \%$ from $3 \mathrm{Zn}\left(\mathrm{PF}_{6}\right)$; (h) 1 equiv. $\mathrm{AgPF}_{6}, \mathrm{CH}_{2} \mathrm{Cl}_{2}, \mathrm{rt}, 2 \mathrm{~min}, 30 \%$. Ar ${ }^{1}=$ Mesityl, $\mathrm{Ar}^{2}=$ 4-methoxyphenyl. spectrum of $\mathbf{3 N i}\left(\mathbf{P F}_{6}\right)$ in toluene exhibited a characteristic band in the NIR region around $880 \mathrm{~nm} . \mathbf{3 C u}\left(\mathbf{P F}_{6}\right), \mathbf{3 Z n}\left(\mathbf{P F}_{6}\right)$, and $\mathbf{3 H}_{\mathbf{2}}\left(\mathbf{P F}_{\mathbf{6}}\right)$ also displayed electrochemical and optical properties that were quite similar to those of $\mathbf{3 N i}\left(\mathbf{P F}_{\mathbf{6}}\right)$. In the case of $\mathbf{3 C u}\left(\mathbf{P F}_{\mathbf{6}}\right)$, a magnetic interaction between the paramagnetic $\mathrm{Cu}$ (II) center and the $\pi$-radical is possible. In fact, neither EPR nor NMR signals were observed, which was presumably due to large zero-field splitting and the contribution of the triplet state, respectively. However, the assignment of the ground state is under discussion. Intriguingly, $\mathbf{3} \mathbf{M g}$ was found to catalyze the dimerization of a phenyl Grignard reagent in the presence of air. NMR and EPR experiments suggested a mechanism involving a $20 \pi / 19 \pi$ redox cycle of $3 \mathbf{M g}$, as shown in Fig. 4 . Shinokubo et al. also reported the diazaporphyrin 4 without substituents on the meso-nitrogen atoms. ${ }^{9}$ In this case, a $19 \pi$ species of the radical cation was not observed from the oxidation of the $20 \pi$ species or the reduction of the $18 \pi$ species 5 , which was presumably due to facile disproportionation of the cationic intermediate.

Osuka et al. synthesized the diphenylamine-fused porphyrins 6 and 7 (Fig. 5). ${ }^{\mathbf{1 0}}$ The lone-pair electrons of the embedded nitrogen atom were well conjugated with the extended porphyrin conjugated network, which caused a decrease in oxidation potentials. Chemical $1 \mathrm{e}^{-}$oxidation gave the corresponding radical cations, both as unstable species. One of the degradation products was a $\beta$-chlorinated species, which indicated high spin density and reactivity at the $\beta$-position next to the fused moiety. To suppress this degradation pathway, 6 and 7 were chlorinated to give 8 and $\mathbf{9}$. Chemical oxidation of $\mathbf{8}$ and $\mathbf{9}$ gave $\mathbf{8}\left(\mathbf{S b C l}_{\mathbf{6}}\right)$ and $\mathbf{9}\left(\mathbf{S b C l}_{\mathbf{6}}\right)$, respectively, which were found to be extremely stable towards air, water, and silica gel column chromatography. As a result of this success, the diarylaminefused porphyrin dimers $\mathbf{1 0}$ and $\mathbf{1 1}$ were prepared and their oxidation to the corresponding diradicals was attempted. ${ }^{\mathbf{1 1}}$ Upon oxidation with magic blue, however, 10 and $\mathbf{1 1}$ were
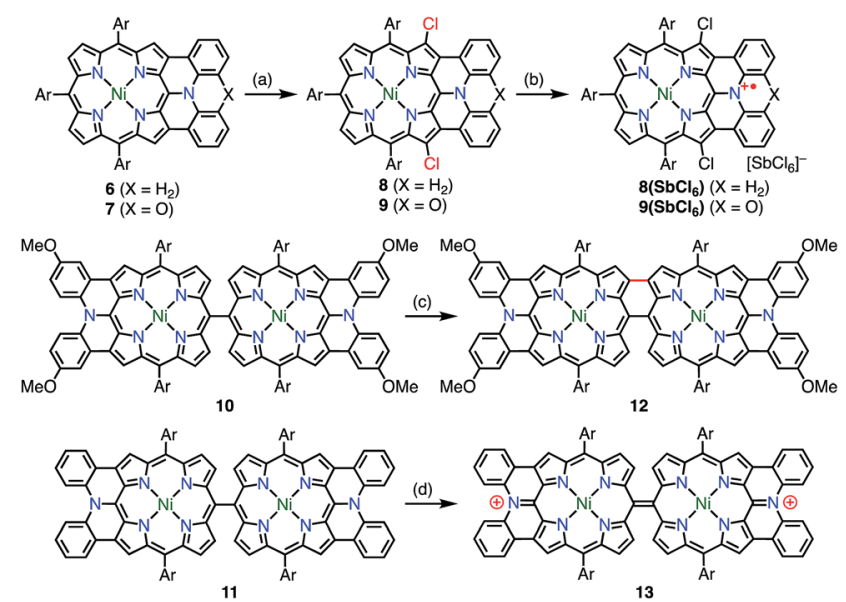

Fig. 5 Diarylamine-fused porphyrins. (a) 2.2 equiv. Palau'chlor, $\mathrm{CHCl}_{3}$, $0{ }^{\circ} \mathrm{C}$ to rt, $87 \%$ for $8,77 \%$ for 9 ; (b) 1.1 equiv. magic blue, $\mathrm{CH}_{2} \mathrm{Cl}_{2}, \mathrm{rt}$, $10 \mathrm{~min}, 79 \%$; (c) 6.0 equiv. magic blue, $\mathrm{CH}_{2} \mathrm{Cl}_{2}, \mathrm{rt}, 15 \mathrm{~min}$, then $\mathrm{H}_{2}$ $\mathrm{NNH}_{2} \cdot \mathrm{H}_{2} \mathrm{O}, 91 \%$; (d) 2.2 equiv. magic blue, $\mathrm{CH}_{2} \mathrm{Cl}_{2}, 10 \mathrm{~min}, 72 \% . \mathrm{Ar}=$ 3,5-di-tert-butylphenyl. 
transformed into the partially fused dimer $\mathbf{1 2}$ and the closedshell quinonoidal species 13, respectively, instead of openshell diradicals.

\subsection{Stabilizing radical anions is a challenge}

Although the properties of $1 \mathrm{e}^{-}$-reduced porphyrin radical anions have been investigated, ${ }^{12}$ the isolation of stable radical anions of porphyrinoids has remained challenging. The reason is simply because porphyrinoids are usually electron-rich, and their radical anions are even more easily oxidized under aerobic conditions. Thus, the isolation of porphyrin radical anions has been difficult so far.

Whereas the SOMO orbital of radical cations reflects the characteristics of the HOMO of their neutral precursors, the SOMO orbital of radical anions represents the characteristics of the LUMO of their precursors. Therefore, the radical anions of porphyrinoids should have different electronic states from those of the radical cations, and it is also desired to investigate such radical anion species. Because most aromatic porphyrinoids have a $[4 n+2] \pi$-system, $[4 n+1] \pi$-radicals are easily accessible via the one-electron oxidation of neutral aromatic porphyrinoids, but $[4 n+3] \pi$-radicals are relatively difficult to generate. To the best of our knowledge, only two strategies for generating $[4 n+3] \pi$-radicals have been reported: (1) oxidative generation from stable $[4 n] \pi$-species ${ }^{\mathbf{8 , 1 3 , 1 4}}$ and (2) the incorporation of a positively charged center into the electron-deficient chromophore to balance the charge. ${ }^{15}$ Fig. 6 summarizes the important orbitals and optical transitions of a neutral molecule, a radical cation, and a radical anion of porphyrin. Both radical anions and cations display similar $\mathrm{P}_{1}$ and $\mathrm{P}_{2}$ absorption bands. Although the origins of the $\mathrm{P}_{2}$ bands are similar for radical anions and radical cations, those of the $\mathrm{P}_{1}$ bands are different. Here, we use the terms $P_{1}$ and $P_{2}$ bands to indicate the lowestenergy transition $\left(\mathrm{P}_{1}\right)$ and the following $\mathrm{Q}$-like $\left(\mathrm{P}_{2}\right)$ band. ${ }^{16,17}$

\section{Substituent-centered radicals}

\subsection{Heme catabolism and meso-oxy radicals}

Heme is an iron complex of porphyrin that plays crucial roles in catalysis in heme proteins. However, once heme is released
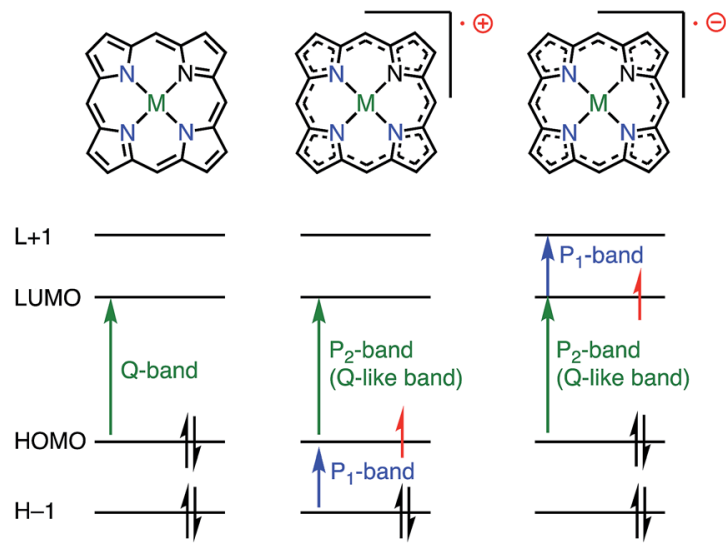

Fig. 6 Difference between radical cation and anion. from the protein, it causes toxicity by generating reactive oxygen species. Therefore, the catabolism of heme is critically important in maintaining homeostasis. Because the first step of the catabolic process is known to be oxidation by heme oxygenase to give meso-oxyheme $15,{ }^{18}$ its derivatives have attracted great interest (Fig. 7). The structure of $\mathbf{1 5}$ in heme oxygenase was determined to be 15A, but the reactivity that was observed toward molecular oxygen implied the contribution of the $\pi$ radical 15B. ${ }^{19}$ Although Bonnett et al. reported 1\% paramagnetism for the free base $\beta$-octaethyl-meso-hydroxyporphyrin $\mathbf{1 8 \mathbf { H } _ { 2 }}$ in $1970,^{\mathbf{2 0}}$ it was a long time until the first structural characterization of the paramagnetic species, i.e., the meso-oxy radical (oxophlorin radical), in 1992. ${ }^{21}$ Fuhrhop et al. investigated the reactivity of $\mathrm{Zn}(\mathrm{II})$ and $\mathrm{Ni}(\mathrm{II})$ complexes of the meso-oxy radical $19 M(M=N i, Z n)$ generated in situ and found rapid and irreversible dimerization at the 15-position. ${ }^{22}$

Balch et al. later investigated a series of $\beta$-octaethylporphyrin (OEP) meso-oxy radicals. ${ }^{23}$ They found that the oxidation of $\mathrm{Zn}$ (II) and $\mathrm{Ni}(\mathrm{II})$ meso-hydroxy OEP $\mathbf{1 8 M}$ in the presence of pyridine gave the meso-oxy radicals $21 \mathrm{Zn}$ and $\mathbf{2 1 N i}$ as stable compounds (Fig. 8). ${ }^{21,24} \mathrm{X}$-ray diffraction analysis confirmed the axial coordination of the pyridine on the central metal. The coordinated pyridine was demonstrated to effectively stabilize the radical, because the removal of the pyridine led to the instantaneous dimerization of the radical. The radical $21 Z n$ had a short $\mathrm{C}_{\text {meso }}{ }^{-}$ O bond (1.268 $)$ in comparison to that of $18 Z n$ (1.392 $\AA$ ), which is a common feature of meso-oxy radicals. In $21 \mathrm{Ni}$, the

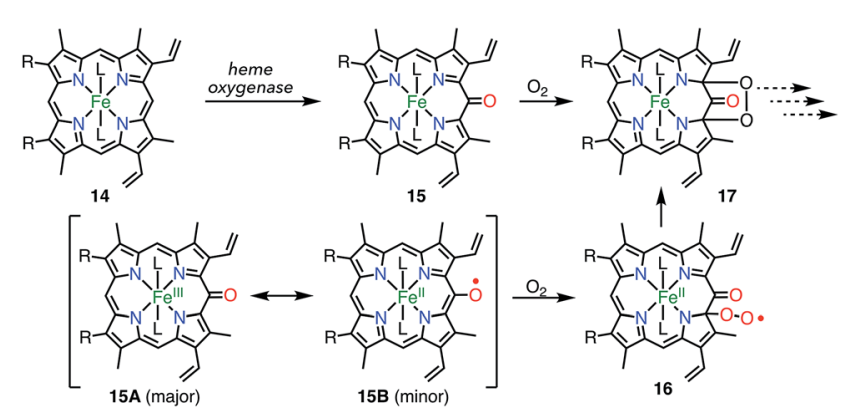

Fig. 7 Heme catabolism.

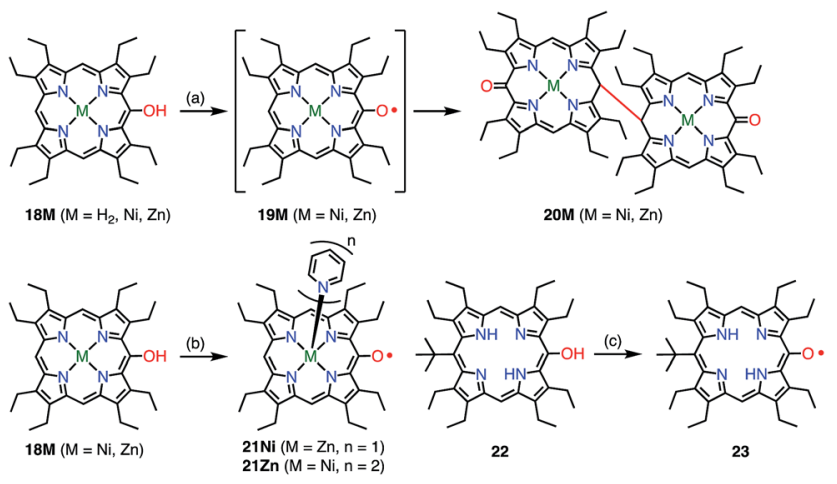

Fig. 8 Stable OEP meso-oxy radicals. (a) Electrochemical oxidation in $\mathrm{CH}_{2} \mathrm{Cl}_{2}$; (b) $\mathrm{I}_{2}$, pyridine, $\mathrm{rt}, 15 \mathrm{~min}, 48 \%$ for $21 \mathrm{Ni}$; air, pyridine for $21 \mathrm{Zn}$; (c) air, daylight, $\mathrm{CH}_{2} \mathrm{Cl}_{2}, 90 \%$. 
octahedrally coordinated $\mathrm{Ni}(\mathrm{II})$ atom had a high-spin $(S=1)$ state as evidenced by an increase in the $\mathrm{Ni}-\mathrm{N}$ distance, which arose from population of the $\mathrm{d}_{x_{2}-y_{2}}$ orbital. However, the EPR spectrum of $21 \mathrm{Ni}$ in pyridine displayed a sharp signal at $g=$ 2.006 , and its magnetic moment was determined to be $2.5(2) \mu_{\mathrm{B}}$, which indicated the $S=1 / 2$ character of the ground state. These results were interpreted in terms of an antiferromagnetic interaction between the porphyrin $\pi$-radical and the high-spin $\mathrm{Ni}(\mathrm{II})$ center.

Smith et al. synthesized the free-base meso-oxy radical $\mathbf{2 3}$ bearing a tert-butyl group at the 15-position. Steric protection at the 15-position, where the highest spin density was expected, led to enhanced stability. ${ }^{25}$ In fact, 23 displayed improved stability but underwent $30 \%$ degradation after two weeks in solution. By employing this strategy, the authors demonstrated an elegant way to construct meso-meso-linked oxophlorin oligomers by controlling radical-radical coupling. ${ }^{26}$

Osuka et al. attempted the synthesis of 15,30-bis(meso-free) [26]hexaphyrin(1.1.1.1.1.1) $\mathbf{2 4 .}^{13}$ The authors obtained 24 together with the meso-oxy radical 25 via the aerobic oxidation of 24 (Fig. 9). X-ray diffraction analysis of 25 revealed a planar structure with a short $\mathrm{C}_{\text {meso }}-\mathrm{O}$ bond length of $1.281 \AA$, which indicated a highly delocalized spin distribution. As is typical for radical porphyrinoids, 25 displayed quite reversible oxidation and reduction waves with a small redox gap of $0.48 \mathrm{~V}$. Furthermore, Osuka et al. found that the oxidation of $\mathbf{2 4}$ upon metalation with $\mathrm{Ni}$ (II) followed by demetalation gave the bis (meso-oxy) diradical 26. ${ }^{27} 26$ was shown to be a stable nonKekulé diradical, because SQUID magnetometry confirmed the singlet nature of its ground state with $J / k_{\mathrm{B}}=-645 \mathrm{~K}$, and CASSCF $(2,2)$ calculations showed an open-shell singlet diradical ground state with a diradical index of 0.62 . Reflecting the singlet nature of the ground state, the ${ }^{1} \mathrm{H}$ NMR spectrum of 26 displayed signals due to $\beta$-protons at 8.0 and $9.6 \mathrm{ppm}$, as well as a signal due to the inner $\mathrm{NH}$ group at $4.5 \mathrm{ppm}$ at $-80{ }^{\circ} \mathrm{C}$ in $\mathrm{CD}_{2} \mathrm{Cl}_{2}$, which indicated a diatropic ring current in the $26 \pi$ aromatic system. These signals became broader upon an increase in temperature owing to the population of the triplet diradical state. The aromaticity of $\mathbf{2 6}$ was further confirmed by theoretical calculations: an $\operatorname{NICS}(0)$ of $-8.2 \mathrm{ppm}$ and a net clockwise (diamagnetic) flow of current density in anisotropy of

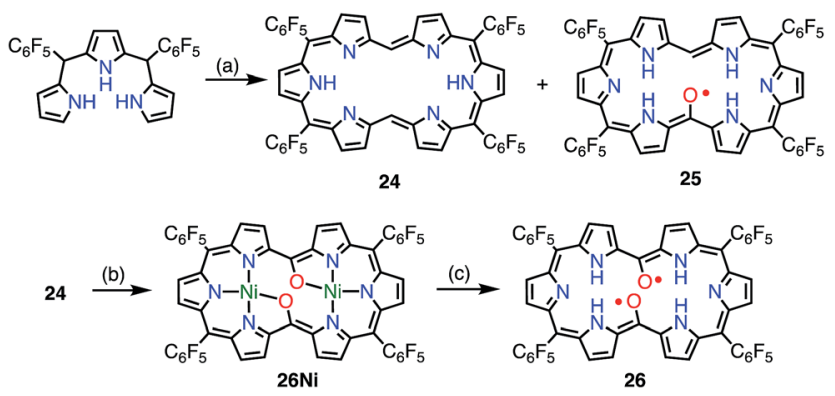

Fig. 9 Hexaphyrin mono- and bis(meso-oxy) radicals. (a) 22 equiv. $\mathrm{HC}(\mathrm{OMe})_{3}, 17$ equiv. $\mathrm{MeSO}_{3} \mathrm{H}, \mathrm{MS3A}, \mathrm{CH}_{2} \mathrm{Cl}_{2}, 0^{\circ} \mathrm{C}, 7 \mathrm{~h}$ in the dark, $17 \%$ for 24 and $15 \%$ for 25 ; (b) ca. 10 equiv. $\mathrm{Ni}$ (acac) $2 \cdot \mathrm{nH}_{2} \mathrm{O}, \mathrm{CH}_{2} \mathrm{Cl}_{2} / \mathrm{MeOH}$, rt, 1 h, 24\%; (c) ca. 900 equiv. $\mathrm{MeSO}_{3} \mathrm{H}, \mathrm{CH}_{2} \mathrm{Cl}_{2}, \mathrm{rt}, 30 \mathrm{~min}, 83 \%$. current-induced density (ACID) calculations. To the best of our knowledge, this is the first observation of ground-state openshell aromaticity. ${ }^{28}$

The observed high stabilities of $\mathbf{2 5}$ and $\mathbf{2 6}$ were considered to arise from effective spin delocalization over the large $\pi$-system of the hexaphyrin network. In 2015, however, the subporphyrin meso-oxy radical 28 was found to be very stable (Fig. 10). ${ }^{29}$ mesoHydroxysubporphyrin 27 was readily oxidized to 28 in the open air in solution, and a trace amount of 28 made the ${ }^{1} \mathrm{H}$ NMR spectrum of 27 completely silent, which was presumably due to rapid hydrogen exchange. The oxidation of 27 with $\mathrm{PbO}_{2}$ gave the radical 28 in quantitative yields. An EPR study of 28 revealed hyperfine coupling with the protons of the meso-phenyl groups, as well as the subporphyrin core, which confirmed effective spin delocalization over the whole molecule except for the axial phenyl group. It is noteworthy that even a relatively small porphyrinoid such as $14 \pi$ aromatic subporphyrin efficiently stabilizes the meso-oxy radical.

With the encouragement of these results, the 10,15,20-triarylporphyrin meso-oxy radicals $30 \mathrm{M}\left(\mathrm{M}=\mathrm{H}_{2}, \mathrm{Ni}, \mathrm{Zn}\right)$ were synthesized by Osuka et al. (Fig. 11). ${ }^{30,31}$ In comparison with the OEP-based radicals, the stabilities of the $\mathbf{3 0 M}$ radicals were dramatically increased. Namely, the 30M radicals were stable in solution under ambient conditions and were purified by silica

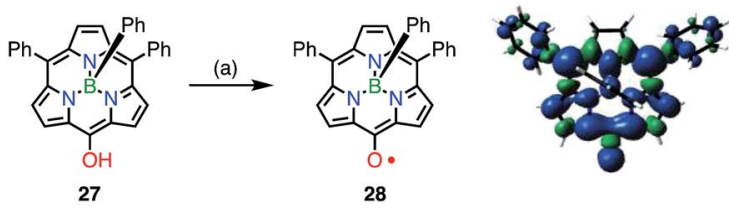

Fig. 10 Synthesis of the subporphyrin meso-oxy radical 28 and plot of spin density distribution of 28 (isovalue $=0.001$ ). (a) 800 equiv. $\mathrm{PbO}_{2}$, $\mathrm{CH}_{2} \mathrm{Cl}_{2}$, rt, quant.
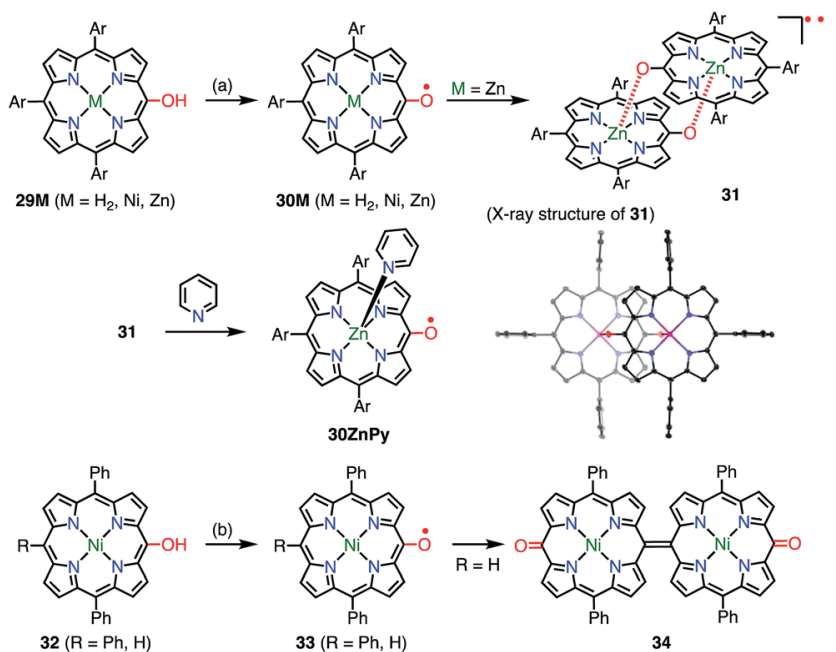

Fig. 11 10,15,20-Triarylporphyrin meso-oxy radicals. (a) 800 equiv. $\mathrm{PbO}_{2}, \mathrm{CH}_{2} \mathrm{Cl}_{2}, \mathrm{rt}, 5 \mathrm{~min}, 86 \%$ for $30 \mathrm{H}_{2}, 91 \%$ for $30 \mathrm{Ni}, 89 \%$ for 31 ; (b) aerobic oxidation for 33,7 equiv. DDQ, $\mathrm{CH}_{2} \mathrm{Cl}_{2}, \mathrm{rt}, 30 \mathrm{~min}, 26 \%$ for 34 . $\mathrm{Ar}=3,5$-di-tert-butylphenyl. Hydrogen atoms and tert-butyl groups in the crystal structure of 31 were omitted for clarity. 
gel column chromatography. The $\mathrm{Zn}$ complex $30 \mathrm{Zn}$ was found to form the complementarily coordinated dimer $\mathbf{3 1}$ both in solution and in the solid state. The dimer $\mathbf{3 1}$ underwent quantitative dissociation into the monomer 30ZnPy on the addition of pyridine. The dimer exhibited a characteristic broad absorption band in the region of $1000-2000 \mathrm{~nm}$, which was assigned to a symmetry-breaking charge transfer band. Although the optical and electrochemical properties were similar to those of the monomers regardless of the central metal, the magnetic properties of the solid states were strongly dependent on the metal. Namely, planar $\mathbf{3 0 H}_{2}$ and $\mathbf{3 0 Z n}$ formed efficiently overlapping $\pi$ dimers, which resulted in strong intermolecular antiferromagnetic interactions with $J / k_{\mathrm{B}}=-790 \mathrm{~K}\left(\mathbf{3 0 H}_{2}\right)$ and $-720 \mathrm{~K}(\mathbf{3 0 Z n})$. On the other hand, 30Ni has a saddle-like structure and forms an offset $\pi$-dimer with $J / k_{\mathrm{B}}=-110 \mathrm{~K}$. A strong intermolecular magnetic interaction via $\pi-\pi$ stacking has also been revealed for porphyrin radical cations. ${ }^{32}$ Coordination with pyridine interrupted such $\pi$-stacking and thus allowed 30ZnPy to display an $M-T$ curve that was typical of monoradical species. Arnold et al. also independently reported the facile aerobic oxidation of mesohydroxyporphyrin 32 to furnish the radical $33 .^{33}$ They showed that the lack of a 15-aryl group allowed the oxidative formation of the 15,15'-linked dimer 34 .

\subsection{Carbon-centered radicals}

In addition to diphenylborane ${ }^{-34}$ and diphenylamine-fused porphyrins, ${ }^{35}$ the synthesis of the diphenylmethane-fused porphyrin 35 was attempted via an intramolecular $\mathrm{C}-\mathrm{H}$ arylation reaction of $36 .{ }^{36}$ Surprisingly, the isolated product was not 35 but the neutral radical $37 \mathrm{Ni}$ via the loss of a hydrogen atom on the fused carbon atom (Fig. 12). The radical 37Ni was very stable under ambient conditions and did not react with hydrogen donors such as $n \mathrm{Bu}_{3} \mathrm{SnH}$ and ascorbic acid. Taking advantage of the robust stability of $\mathbf{3 7} \mathbf{N i}$, its denickelation with sulfuric acid was accomplished to afford the free-base derivative $37 \mathbf{H}_{2}$ in a yield of $51 \%$. The high stabilities of $37 \mathrm{Ni}$ and $\mathbf{3 7 \mathbf { H } _ { 2 }}$ arise from effective spin delocalization over the whole molecule and the structural rigidification. ${ }^{37}$ In a single crystal, both $37 \mathrm{Ni}$ and $37 \mathbf{H}_{2}$ form antiparallel $\pi$-stacked dimers with $\pi-\pi$ distances of 3.51 and $3.56 \AA$ for $37 \mathrm{Ni}$ and 3.56 and $3.61 \AA$ for $\mathbf{3 7} \mathbf{H}_{2}$ together with an offset of 3.4-3.5 $\AA$. The intermolecular exchange interaction in the solid state was determined to be $J / k_{\mathrm{B}}$ $=-391 \mathrm{~K}(\mathbf{3 7 N i})$ and $-279 \mathrm{~K}\left(\mathbf{3} \mathbf{3} \mathbf{H}_{2}\right)$, which reflected the slightly different $\pi-\pi$ distances.

Because the externally fused moiety of $\mathbf{3 7}$ can be regarded as a helicene-like structure, an extended series of $\mathbf{3 7}$ derivatives has been synthesized to obtain stable neutral helically chiral radicals. $^{38} \quad$ The bis(2-methylphenyl)methyl-, bis(2methoxyphenyl)methyl-, and dinaphthylmethyl-fused porphyrins $39 \mathbf{R}(\mathbf{R}=\mathrm{Me}$ or $\mathrm{OMe})$ and $\mathbf{4 1}$ were synthesized via $\mathbf{P d}-$ catalyzed intramolecular fusion reactions (39R) and an oxidative fusion reaction (41). 39R and $\mathbf{4 1}$ are rare examples of stable radicals in which the spin is delocalized over a chiral $\pi$-system. Unfortunately, $39 \mathbf{R}$ and $\mathbf{3 9} \mathbf{R}^{\prime}$ were obtained as a mixture of regioisomers owing to an unexpected rearrangement (39Me/ $39 \mathrm{Me}^{\prime}=32 / 68$ and $\left.390 \mathrm{Me} / 390 \mathrm{Me}^{\prime}=22 / 78\right)$, which was

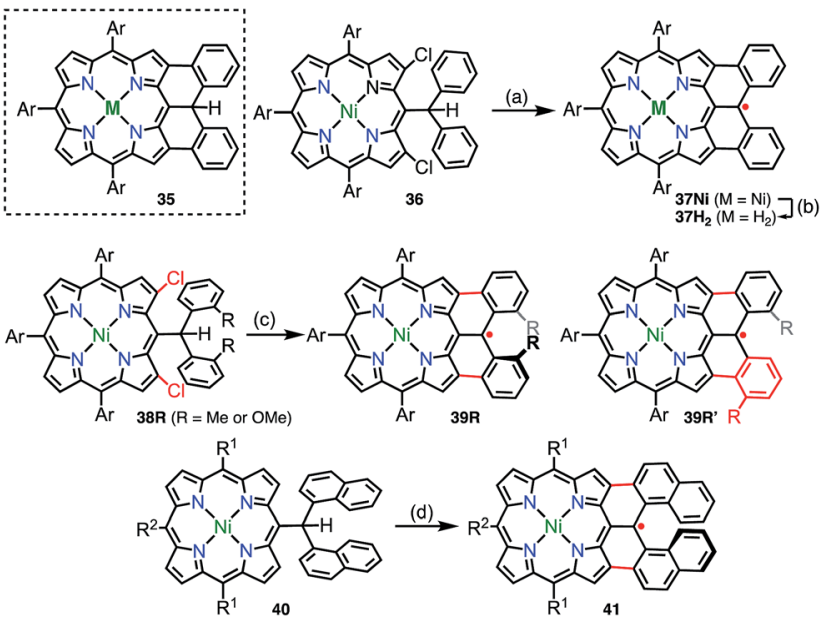

Fig. 12 Diarylmethyl-fused porphyrins. (a) 20 mol\% $\mathrm{Pd}(\mathrm{OAc})_{2}$, 40 mol\% $\mathrm{PCy}_{3} \cdot \mathrm{HBF}_{4}, 5$ equiv. $\mathrm{K}_{2} \mathrm{CO}_{3}$, toluene, reflux, overnight, $72 \%$; (b) $\mathrm{H}_{2} \mathrm{SO}_{4} / \mathrm{CF}_{3} \mathrm{CO}_{2} \mathrm{H}, 0{ }^{\circ} \mathrm{C}$ to rt, $45 \mathrm{~min}, 51 \%$; (c) 20 mol\% $\mathrm{Pd}(\mathrm{OAc})_{2}$, 40 mol\% $\mathrm{PCy}_{3} \cdot \mathrm{HBF}_{4}, 5$ equiv. $\mathrm{K}_{2} \mathrm{CO}_{3}$, toluene, reflux, overnight, $48 \%$ for $39 \mathrm{Me} / 39 \mathrm{Me}^{\prime}, 79 \%$ for $390 \mathrm{Me} / 390 \mathrm{Me}^{\prime}$; (d) 10 equiv. DDQ, 10 equiv. $\mathrm{Sc}(\mathrm{OTf})_{3}$, toluene, $110{ }^{\circ} \mathrm{C}, 1 \mathrm{~h}, 19 \% . \mathrm{Ar}=3,5$-di-tert-butylphenyl, $\mathrm{R}^{1}=$ mesityl, $\mathrm{R}^{2}=4$-methylphenyl.

determined by analyzing $1 \mathrm{e}^{-}$-oxidized closed-shell cations $[39 R]^{+}$. The radical 41 was synthesized from 40 and was optically resolved using chiral HPLC. The circular dichroism spectra of the separated enantiomers exhibited weak but distinct mirror images up to $1400 \mathrm{~nm}$. Because the lowest-energy band was assigned to the $\operatorname{HOMO}(\beta)-\operatorname{SOMO}(\beta)$ transition, the circular dichroism observed in the NIR region indicated the spreading of the corresponding orbitals over the helical skeleton. In contrast to $\mathbf{3 7}$, the radical $\mathbf{4 1}$ did not form a $\pi$-stacked dimer in the solid state, and the intermolecular magnetic interaction was found to be slight (Weiss temperature of $-2.7 \mathrm{~K}$ ), owing to unfavorable steric interactions at the ends of the helices.

\section{3. meso-Aminyl radicals}

In contrast to oxygen- and carbon-centered radicals, aminyl radicals are unstable, and adjacent heteroatoms are usually required for their stabilization. Heteroatoms next to the aminyl center stabilize aminyl radicals via effective spin sharing as seen in the cases of hydrazinyl, oxyaminyl, and thioaminyl radicals. ${ }^{39}$ However, stable aminyl radicals without such adjacent heteroatoms are very rare, and the investigation of stable aminyl radicals without such resonance stabilization is a challenging issue. Osuka et al. attempted the oxidation of the meso-aminosubporphyrin 42R with $\mathrm{PbO}_{2}$ in the expectation that it might give the aminyl radical $43 \mathbf{R}$, but the reaction gave the azosubporphyrin 44R, presumably via 43R (Fig. 13). ${ }^{\mathbf{4 0}}$ Thus, meso(2,4,6-trichlorophenyl)subporphyrin $\mathbf{4 5}$ was prepared and oxidized to provide the subporphyrin meso-aminyl radical 46R in a high yield. Importantly, this radical was found to be fairly stable in spite of its neutral character without resonance stabilization. ${ }^{41}$ The bis(subporphyrinyl)aminyl radical 47 was also synthesized and found to be even more stable. Both the hyperfine coupling constants of the pyrrolic nitrogen atoms $\left(\mathrm{N}^{2}\right.$ 

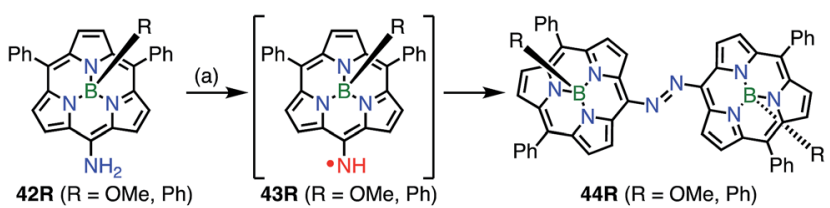

42R $(\mathrm{R}=\mathrm{OMe}, \mathrm{Ph})$ 43R $(\mathrm{R}=\mathrm{OMe}, \mathrm{Ph})$

44R $(\mathrm{R}=\mathrm{OMe}, \mathrm{Ph})$
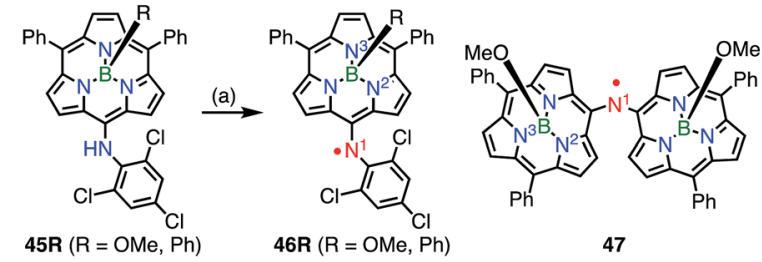

45R $(\mathrm{R}=\mathrm{OMe}, \mathrm{Ph})$

46R $(\mathrm{R}=\mathrm{OMe}, \mathrm{Ph})$

47

Fig. 13 Subporphyrin meso-aminyl radicals. (a) 200 equiv. $\mathrm{PbO}_{2}$ $\mathrm{CH}_{2} \mathrm{Cl}_{2}, \mathrm{rt}, 5-10 \mathrm{~min}, 83 \%$ for $440 \mathrm{Me}, 95 \%$ for $44 \mathrm{Ph}, 88 \%$ for $460 \mathrm{Me}$, $87 \%$ for $46 \mathrm{Ph}$

and $\mathrm{N}^{3}$ in Fig. 13) and DFT calculations indicated a higher spin density on the nitrogen atom in comparison with that in the corresponding oxygen-centered radicals, which was presumably because the $\mathrm{C}=\mathrm{N}$ bond energy is less than that of the $\mathrm{C}=\mathrm{O}$ bond. Whereas both radicals (46Ph and 46OMe) were quite stable, the spin delocalization over the subporphyrin core was more effective in $46 \mathrm{Ph}$ than in $460 \mathrm{Me}$, which may reflect the more electron-rich nature of $\mathbf{4 6 P h}$.

\section{Non-innocent macrocyclic radicals}

In the previous section, we discussed ligand-centered redox processes of $\mathrm{M}$ (II) metalloporphyrinoids that led to the formation of stable radicals owing to the non-innocent ligand ${ }^{42}$ character of porphyrinoids. In this section, we focus on other cases in which the redox-active character of porphyrinoid macrocycles enables the formation of stable radicals. Porphyrinoids can accommodate various metals. When the valence of the metal is mismatched with the cavities of the porphyrinoid and causes the complex to have a net charge, the resulting complexes sometimes tend to balance the charge by releasing or acquiring an electron (Fig. 14). These processes are facilitated by the fairly flexible $\pi$-networks of porphyrinoids.

\subsection{Facile non-innocent behavior of porphyrinoids}

Chandrashekar et al. reported that the metalation with $\mathrm{Ni}(\mathrm{II})$ of oxasmaragdyrin 48, which is an expanded porphyrin bearing three pyrrolic protons, afforded a neutral $\pi$-radical via spontaneous oxidation of the macrocycle (Fig. 15). ${ }^{43}$ The Ni(II) complex 49 displayed a sharp EPR signal at $g=2.0031$ with a linewidth of $11 \mathrm{G}$, which can be assigned to organic $\pi$-radical species. It should be noted that 49 also exhibited a slightly broader but distinct ${ }^{1} \mathrm{H}$ NMR spectrum at $25{ }^{\circ} \mathrm{C}$.

Osuka et al. reported that the metalation of [28]hexaphyrin with $\mathrm{Pd}(\mathrm{II})$ gave the bis-Pd(II) complex 50 together with the Möbius aromatic mono-Pd(II) complex $\mathbf{5 1}$ as a minor product (Fig. 16). ${ }^{\mathbf{1 4}}$ In 50, [28] hexaphyrin acted as an inner $4 \mathrm{NH}$ ligand, but the bridging $\mathrm{Cl}^{-}$ion caused a valence mismatch. As a consequence, the hexaphyrin ligand released one electron to balance the charge to provide the radical 50. The EPR spectrum

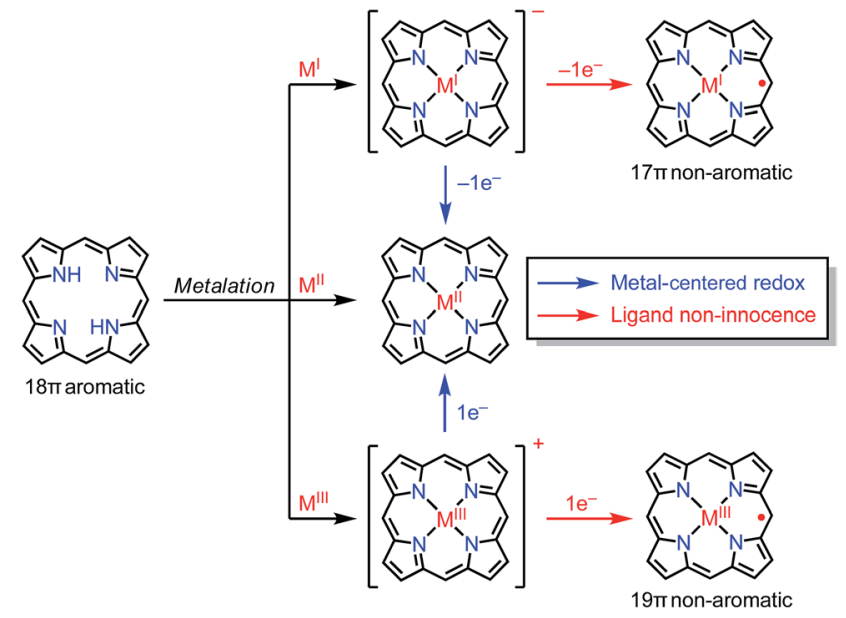

Fig. 14 General concept of ligand non-innocence in porphyrinoids.

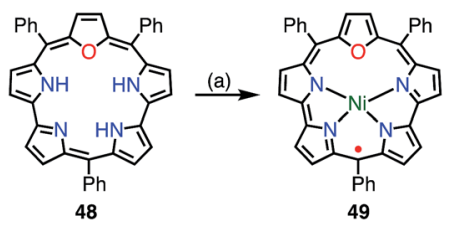

Fig. 15 Metalation with $\mathrm{Ni}\left(\right.$ II) of oxasmaragdyrin. (a) 10 equiv. $\mathrm{NiCl}_{2}$, DMF, reflux, $10 \mathrm{~h}, 10 \%$.

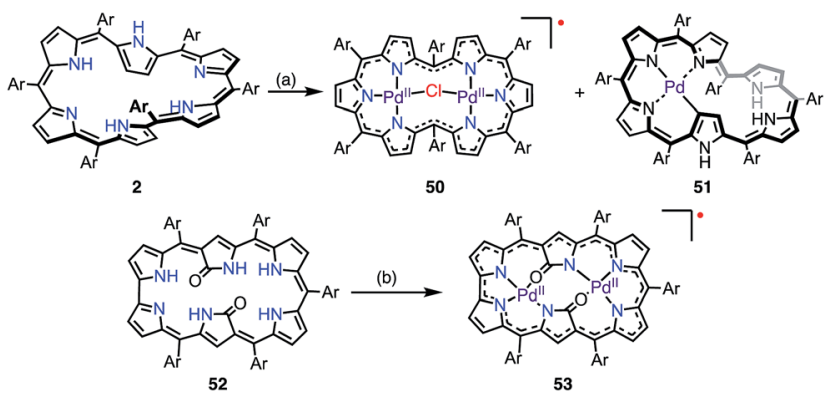

Fig. 16 Metalation of hexaphyrins with $\mathrm{Pd}$. (a) 10 equiv. $\mathrm{PdCl}_{2}, 10$ equiv. $\mathrm{NaOAc}, \mathrm{CH}_{2} \mathrm{Cl}_{2} / \mathrm{MeOH}, 45^{\circ} \mathrm{C}, 24 \mathrm{~h}, 50 \%$ for $50,4 \%$ for 51 ; (b) 10 equiv. $\mathrm{Pd}(\mathrm{OAc})_{2}, \mathrm{CH}_{2} \mathrm{Cl}_{2} / \mathrm{MeOH}, \mathrm{rt}, 10 \mathrm{~h}, 75 \%$. Ar = pentafluorophenyl.

of 50 displayed a signal with an anisotropic $g$-factor of $(2.0084$, 1.9966, 1.9412), which indicated relatively strong spin-orbit coupling with the $\mathrm{Pd}(\mathrm{II})$ metal. The radical $\mathbf{5 0}$ is a rare example that has a delocalized spin over a non-planar conjugation circuit. Furuta et al. also reported a $\pi$-radical of a bis-Pd(II) complex of doubly $\mathrm{N}$-confused hexaphyrin, i.e., 52, which had intriguing $2 \mathrm{NH}-$ and $3 \mathrm{NH}-\mathrm{NNNO}$ cavities for metalation. ${ }^{\mathbf{4 4}}$ The bis-Pd complex 53 displayed an isotropic EPR signal at $g=$ 2.0021. Despite the bulky meso-pentafluorophenyl groups, 53 adopted a $\pi$-stacked structure in the solid state with an interplanar distance of $3.266 \AA$, which was shorter than the sum of the van der Waals radii. This close arrangement may arise from a moderate intermolecular antiferromagnetic interaction owing to the overlap of the SOMOs, which was 
proved by SQUID measurements (Weiss temperature of -42.9 $\mathrm{K})$.

Sessler et al. recently reported the synthesis of the dicarbacorrole dimer $\mathbf{5 4}$, in which the monomers share a fused vinylene moiety in the center (Fig. 17). ${ }^{45}$ The macrocycle 54 has a symmetric structure with two trivalent CCNN cavities. The metalation of $\mathbf{5 4}$ with $\mathrm{Cu}$ afforded the mono- and bis-Cu(III)

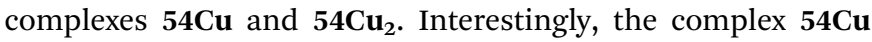
was further metalated with $\operatorname{Pd}($ II) to give the neutral, stable $\pi$ radical 55 via spontaneous oxidation. The spin density of 55 was delocalized only over the Pd-dicarbacorrole segment, which was confirmed by EPR spectroscopy and theoretical calculations. This is a rare example in which the spin density is not fully delocalized over a flat conjugated system.

A valence mismatch between the ligand and metal is not necessary to induce ligand non-innocence. The [46]decaphyrin bis-Zn(II) complex $\mathbf{5 7}$ has a rigid structure and an inner cavity that is suitable for the coordination of a divalent metal in a linear manner. Osuka et al. examined the metalation of $\mathbf{5 7}$ with $\mathrm{Cu}(\mathrm{II})$ to obtain the unprecedented linearly coordinated $\mathrm{Cu}(\mathrm{II})$ complex $\mathbf{5 8}^{\prime} .^{46}$ However the resulting copper complex displayed a narrow EPR signal at $g=2.0177$, which clearly indicated its purely organic $\pi$-radical character (Fig. 18). With the aid of theoretical calculations, the product was best interpreted as a $\mathrm{Zn}$ (II)-Cu(I)-Zn(II) complex of [45]decaphyrin, i.e., 58. These results indicated that almost instantaneous intramolecular electron transfer occurred from the decaphyrin ligand to the $\mathrm{Cu}$ (II) ion to generate the stable radical 58. Interestingly, the $45 \pi$ non-aromatic radical 58 exhibited a broad absorption band in the NIR region that extended to $2100 \mathrm{~nm}$.

\subsection{Tetraazaporphyrin phosphorus(v) complex}

Kobayashi et al. reported the phosphorus(v) complex of tetraazaporphyrin 61 as an air-stable compound with a $19 \pi$ electronic structure (Fig. 19). ${ }^{15}$ The complex 61 was synthesized by the insertion of phosphorus(v) into 59 followed by reduction with triethylamine (TEA). Solid samples of $\mathbf{6 1}$ were inert under ambient conditions for a year. The exceptional stability of $\mathbf{6 1}$ was ascribed to the electron-deficient nature of tetraazaporphyrins, in which the four meso-carbons of porphyrin are replaced by four nitrogen atoms. It was also suggested that

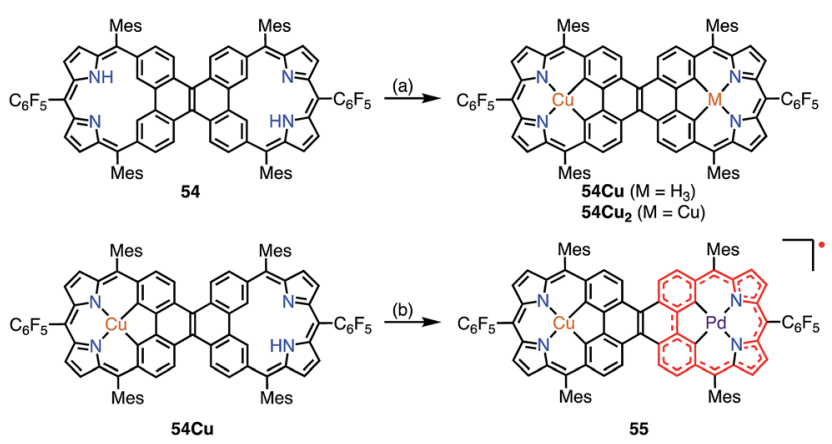

Fig. 17 Metalation of dicarbacorroles with $\mathrm{Cu}(\mathrm{II})$ and $\mathrm{Pd}(\mathrm{II})$. (a) $\mathrm{Cu}(\mathrm{OAC})_{2} \cdot \mathrm{H}_{2} \mathrm{O}$ in $\mathrm{CHCl}_{3}$, reflux, $48 \mathrm{~h}$; (b) $\mathrm{Pd}(\mathrm{PhCN})_{2} \mathrm{Cl}_{2}$ in $\mathrm{PhCN}$, $180{ }^{\circ} \mathrm{C}, 2 \mathrm{~h}, 89 \%$.
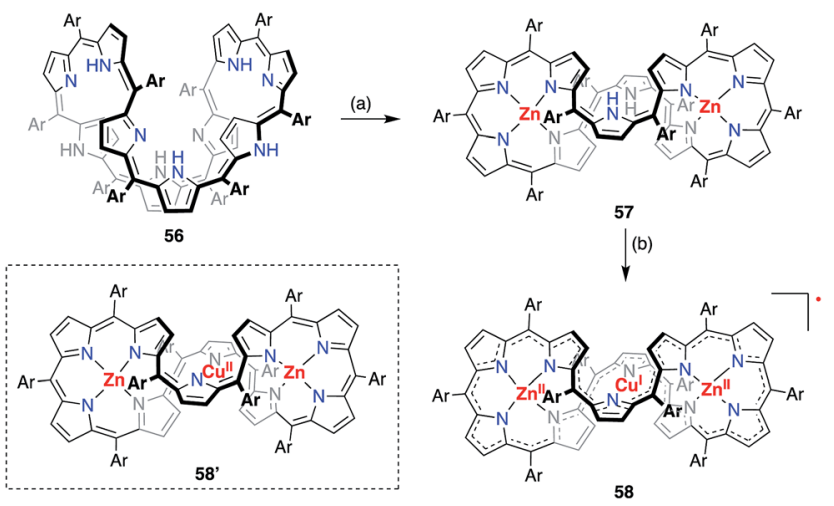

Fig. 18 Synthesis of the decaphyrin $\mathrm{Zn}($ II) $-\mathrm{Cu}(\mathrm{I})-\mathrm{Zn}($ (I) complex 58. (a) 5 equiv. $\mathrm{Zn}(\mathrm{OAc})_{2} \cdot 2 \mathrm{H}_{2} \mathrm{O}, 5$ equiv. $\mathrm{NaOAc}, \mathrm{MeOH}$, reflux, $2 \mathrm{~h}, 61 \%$; (b) 10 equiv. $\mathrm{Cu}(\mathrm{OAc})_{2}, 10$ equiv. $\mathrm{NaOAc}, \mathrm{MeOH}, \mathrm{rt}, 4 \mathrm{~h}, 72 \% . \mathrm{Ar}=$ pentafluorophenyl.

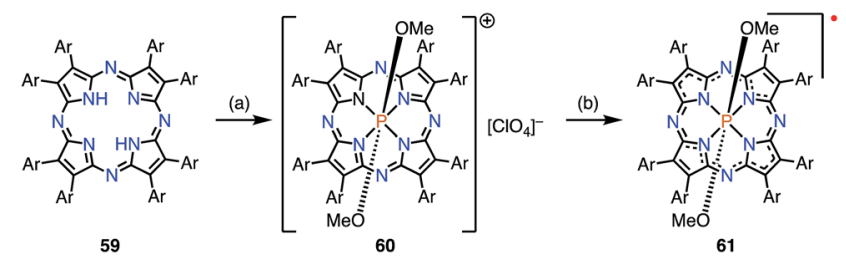

Fig. 19 Synthesis of 61 . (a) $\mathrm{POBr}_{3}$ (200 equiv.), pyridine, $90{ }^{\circ} \mathrm{C}, 15 \mathrm{~h}$, then $\mathrm{CH}_{2} \mathrm{Cl}_{2} / \mathrm{MeOH}$, rt, 1 d. 60 was separated by $\mathrm{SiO}_{2}$ column chromatography $\left(\mathrm{CH}_{2} \mathrm{Cl}_{2} / \mathrm{MeOH} / \mathrm{CF}_{3} \mathrm{CO}_{2} \mathrm{H}=90 / 9.5 / 0.5\right)$, then $\mathrm{NaClO}_{4}$, $\mathrm{CH}_{2} \mathrm{Cl}_{2} / \mathrm{MeCN}$, rt, $12 \mathrm{~h}, 56 \%$; (b) 61 was separated by $\mathrm{Al}_{2} \mathrm{O}_{3}$ column chromatography (eluent: $\mathrm{CH}_{2} \mathrm{Cl}_{2} / \mathrm{TEA}=99.5 / 0.5$ ) without isolating 60, $44 \%$.

charge neutralization by the central cationic phosphorus atom and steric protection by the peripheral bulky groups were both important. The radical $\mathbf{6 1}$ exhibited a very low electrochemical oxidation potential of $-0.36 \mathrm{~V} v s . \mathrm{Fc} / \mathrm{Fc}^{+}$in $o$-dichlorobenzene.

\subsection{Protonation-induced radical formation}

Protonation of the pyrrolic nitrogen atoms in the inner cavity strongly affected both the electronic and the structural properties of expanded porphyrinoids. ${ }^{47}$ For example, Naruta et al. synthesized the core-modified sapphyrin analogue 62, which contained two exo-methylene bonds (Fig. 20). Protonation of 62 induced facile $2 \mathrm{e}^{-}$oxidation to give the trication $\mathbf{6 3 X}_{3}\left(\mathrm{X}=\mathrm{Cl}^{-}\right.$, $\left.\mathrm{CF}_{3} \mathrm{CO}_{2}{ }^{-}\right) .^{48}$ The formation of $\mathbf{6 3} \mathrm{X}_{3}$ was reversible, depending on the acid concentration, as evidenced by titration experiments. $63 \mathrm{X}_{3}$ displayed a sharp EPR signal at $g=2.0041$ and an NIR absorption band extending to $1400 \mathrm{~nm}$, whereas the precursor 62 absorbed visible light up to $700 \mathrm{~nm}$. X-ray diffraction analysis of $\mathbf{6 3 X}_{\mathbf{3}}$ revealed a distorted structure, which indicated minimal spin delocalization through the phenanthroline bridge. The intramolecular spin-spin interaction was proved by a SQUID study to be antiferromagnetic with $J / k_{\mathrm{B}}$ $=-680 \mathrm{~K}$. Besides these interesting redox behaviors upon protonation, 62 was also used as a fluorescent monitoring agent for sensing $\mathrm{Mg}^{2+}$ ions. $^{49}$ 

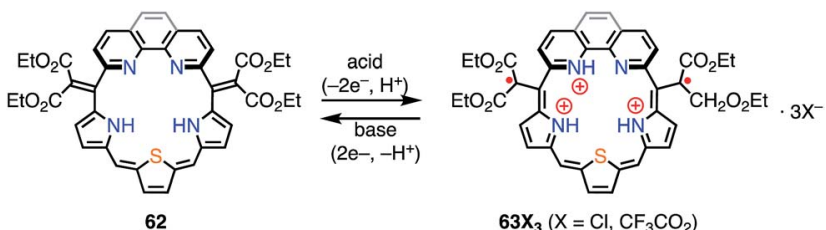

Fig. 20 Protonation behavior of the modified sapphyrin 62

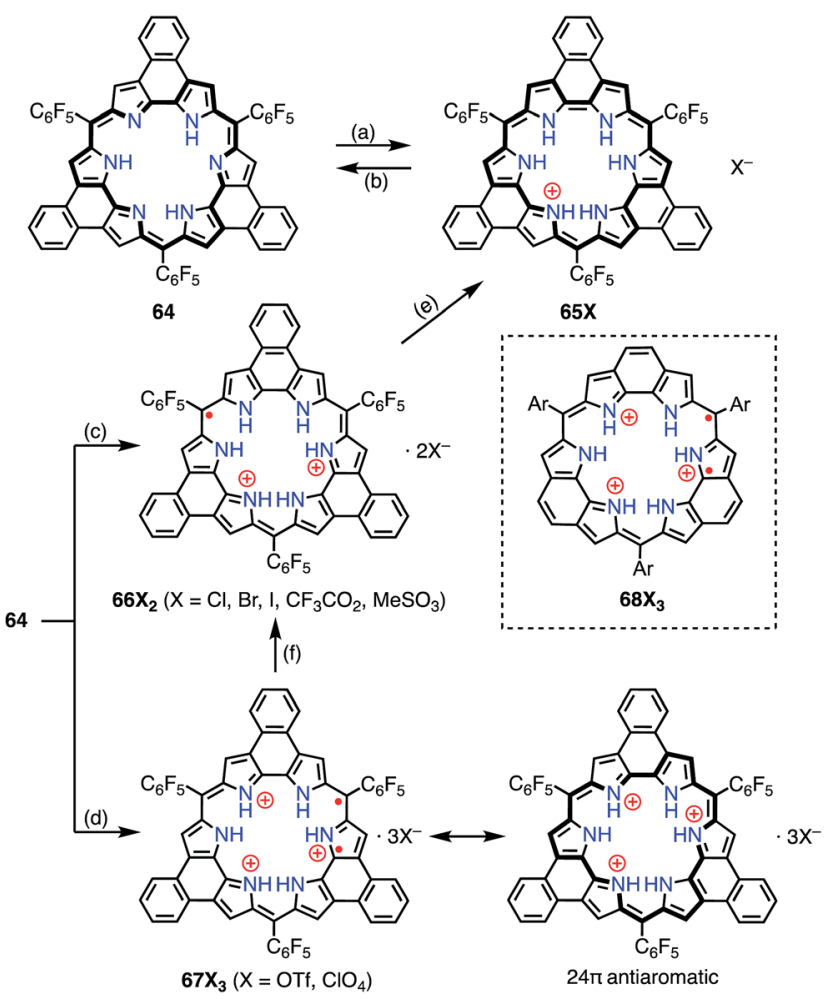

Fig. 21 Protonation-induced formation of the planar rosarin derivatives 64. (a) Saturated $\mathrm{Na}_{2} \mathrm{~S}_{2} \mathrm{O}_{4}$ (aq), $\mathrm{CH}_{2} \mathrm{Cl}_{2}, \mathrm{rt}, 30 \mathrm{~min}, 87 \%$; (b) $\mathrm{MnO}_{2}$ or triethylamine; (c) $\mathrm{HX}\left(\mathrm{X}=\mathrm{Cl}, \mathrm{Br}, \mathrm{l}, \mathrm{CF}_{3} \mathrm{CO}_{2}, \mathrm{MeSO}_{3}\right), \mathrm{CH}_{2} \mathrm{Cl}_{2}, \mathrm{rt}$; (d) $\mathrm{HX}\left(\mathrm{X}=\mathrm{OTf}, \mathrm{ClO}_{4}\right), \mathrm{CH}_{2} \mathrm{Cl}_{2}, \mathrm{rt}$; (e) $\mathrm{Me}_{10} \mathrm{FC}, \mathrm{HI}$; (f) $\operatorname{TBAX}(\mathrm{X}=\mathrm{Cl}, \mathrm{Br}, \mathrm{l})$, $\mathrm{CH}_{2} \mathrm{Cl}_{2}, \mathrm{rt}$.

Sessler et al. reported the protonation behaviors of the $o$ phenylene-bridged annulated rosarin 64 (Fig. 21). ${ }^{50}$ The protonation of 64 with $\mathrm{HX}\left(\mathrm{X}=\mathrm{Cl}, \mathrm{Br}, \mathrm{CF}_{3} \mathrm{CO}_{2}, \mathrm{MeSO}_{3}\right)$ afforded $\mathbf{6 6}_{2}$ via a protonation-coupled electron transfer (PCET) process. The counterion has a great influence in this PCET process. For example, the protonation of $\mathbf{6 4}$ with $\mathrm{HOTf}$ or $\mathrm{HClO}_{4}$ only gave the tri-protonation product $\mathbf{6 7} \mathbf{X}_{3}$, but the subsequent addition of tetrabutylammonium salts (e.g., TBAX; $\mathrm{X}=\mathrm{Cl}, \mathrm{Br}$ ) promoted the PCET process to give $\mathbf{6 6}_{\mathbf{2}}$. When $\mathrm{HI}$ was used as an acid, the further reduction of $\mathbf{6 6}_{\mathbf{2}}$ to $\mathbf{6 5 X}$ proceeded with decamethylferrocene.

Intriguingly, Fukuzumi et al. revealed that $67 \mathbf{X}_{3}$ and the related rosarin derivatives $6 \mathbf{6 8} \mathrm{X}_{3}$ were diradicals with $24 \pi$ antiaromatic electronic structures. ${ }^{51}$ The intramolecular spin-spin interaction was found by VT-EPR measurements to be only weakly ferromagnetic $\left(\Delta E_{\mathrm{ST}} \approx+80 \mathrm{~J} \mathrm{~mol}^{-1}\right.$ at $4 \mathrm{~K}$ for $\left.68 \mathrm{X}_{3}\right)$. Despite the weak magnetic interaction, the spin-spin distance was estimated to be short at $3.6 \AA$ from the zero-field splitting value $(D=57.7 \mathrm{mT})$ on the assumption of the point dipole approximation. DFT calculations revealed the $a_{1}{ }^{\prime \prime}$ and $a_{2}{ }^{\prime \prime}$ symmetry of the SOMOs of the parent trication $\mathbf{6 8 X}_{3}$ These MOs are non-disjoint and should be responsible for the ferromagnetic interaction.

\section{4. "Hidden" non-innocence}

A corrole 69 is a one-methine-carbon-contracted porphyrin that has three inner pyrrolic NH protons and thus acts as a trivalent ligand (Fig. 22). ${ }^{52}$ In addition, corroles can incorporate metals in higher oxidation states such as $\mathrm{Fe}(\mathrm{v}), \mathrm{Mn}(\mathrm{vI})$, and $\mathrm{Cr}(\mathrm{vI})$. These complexes have often been used as mimics of biological intermediates. ${ }^{53} \mathrm{Fe}(\mathrm{IV}), \mathrm{Ni}(\mathrm{II})$, and $\mathrm{Cu}(\mathrm{II})$ corroles are all known as ligand-centered radical species. ${ }^{54} \mathrm{Here}$, we review $\mathrm{Cu}(\mathrm{II})$ corroles in detail.

Although the copper complex $\mathbf{7 0}$ was first synthesized in $1965,{ }^{55}$ its electronic structure and the oxidation state of the $\mathrm{Cu}$ center have for a long time been under discussion. ${ }^{56}$ The observed diamagnetic character can be interpreted in terms of the $\mathrm{Cu}$ (III) corrole $\mathbf{7 0 A}$ or antiferromagnetically coupled $\mathrm{Cu}$ (II) and the corrole radical cation 70B. In 2010, Pierloot et al. suggested a non-innocent ligand character and a decreased singlettriplet energy gap for $\mathbf{7 0}$ using $a b$ initio calculations. ${ }^{57}$ In 2005, Kadish et al. and Sarkar et al. independently reported the existence of non-innocent ligand character in $\mathrm{Cu}(\mathrm{II})$ corroles by comparison with the corresponding silver corroles. ${ }^{58 a, b}$ The latter group also mentioned the existence of a mixed-orbital configuration in which the $\mathrm{Cu}$ corrole exists as an intermediate species between $\mathrm{Cu}$ (II) and $\mathrm{Cu}(\mathrm{III})$ complexes. In 2006, Lemon et al. further investigated the electronic structure of the copper corrole $70{ }^{58 c} \mathrm{An}$ EPR study of 70 showed a doublet signal with hyperfine coupling with a ${ }^{65} \mathrm{Cu} /{ }^{63} \mathrm{Cu}$ nucleus $(I=3 / 2)$, which is characteristic of $\mathrm{Cu}(\mathrm{II})$ species. Further experimental support was given by X-ray photoelectron spectroscopy (XPS), which revealed shake-up satellite peaks in the $\mathrm{Cu} 2 \mathrm{p}$ region that were characteristic of $\mathrm{Cu}$ (II) ions. The magnetic interaction between the corrole $\pi$-radical and the $\mathrm{Cu}(\mathrm{II})$ center was found

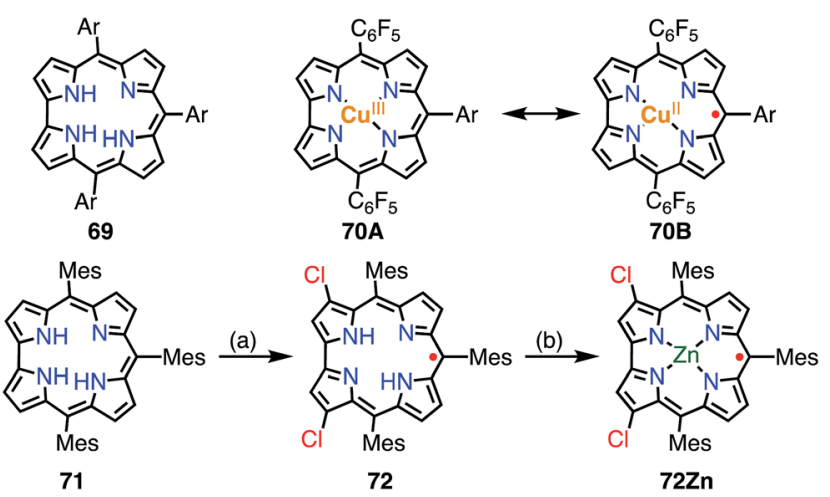

Fig. 22 Two plausible electronic structures of $\mathrm{Cu}(॥)$ corrole (top) and corrole radicals. (a) $\mathrm{WCl}_{6}, \mathrm{~W}(\mathrm{CO})_{6}(2: 1), \mathrm{PhCN}, 200{ }^{\circ} \mathrm{C}, 8 \mathrm{~h}, 4-7 \%$; (b) $\mathrm{Zn}(\mathrm{OAc})_{2} \cdot 2 \mathrm{H}_{2} \mathrm{O}$, pyridine, $50{ }^{\circ} \mathrm{C}, 2 \mathrm{~h}, 77 \%$. $\mathrm{Ar}=4-$ methoxycarbonylphenyl. 
by VT-NMR measurements to be strongly antiferromagnetic $\left(\Delta E_{\mathrm{ST}}=-13.9 \pm 0.7 \mathrm{~kJ} \mathrm{~mol}^{-1}\right)$. In this case, ligand-centered spin can only be observed when the paramagnetic character of the metal is eliminated, which is known as hidden non-innocence. The electronic structure of $\mathrm{Cu}$ corroles has been extensively discussed for decades from various experimental and theoretical aspects. However, further studies are required for a clear understanding of their electronic structure, in particular $\mathrm{Cu}(\mathrm{II}) /$ $\mathrm{Cu}(\mathrm{III})$ mixed states and meso-substituent effects.

Recently, Bröring et al. synthesized the free corrole radical 72 and its $\mathrm{Zn}$ (II) complex 72Zn by the oxidation of the meso-triarylcorrole 71. Curiously, the oxidation of 71 with $\mathrm{WCl}_{6}$ and $\mathrm{W}(\mathrm{CO})_{6}$ gave compound 72 with concurrent $\beta$-chlorination, which indicated high spin densities on the $\beta$-carbons. Protection of these reactive $\beta$-positions is required for stabilization of the radicals. ${ }^{59}$ Both 72 and $\mathbf{7 2 Z n}$ were remarkably stable and exhibited split Soret-like bands around $400 \mathrm{~nm}$ and broad Qlike bands in the region of $500-800 \mathrm{~nm}$.

Brückner et al. recently reported the Siamese-twin porphyrin 73, which had a hexaphyrin-like skeleton with two pyrazole rings. ${ }^{60}$ The free base 73 had a flexible structure without macrocyclic aromaticity. The bis-Cu(II) complex $\mathbf{7 4}$ was shown to be twisted and exhibit a ferromagnetic interaction with $J / k_{\mathrm{B}}=$ $+23.5 \mathrm{~K}$ between the two $S=1 / 2 \mathrm{Cu}$ (II) centers (Fig. 23). This magnetic interaction may arise from orbital orthogonality induced by the molecular twist. Two years later, Beer et al. investigated the oxidation of $74 .^{61}$ Stepwise $1 \mathrm{e}^{-}$and $2 \mathrm{e}^{-}$oxidations of $\mathbf{7 4}$ were achieved with $\mathrm{AgBF}_{4}$. The monocation $\mathbf{7 4}\left(\mathbf{B F}_{4}\right)$ was found to be a species with a total $S=1 / 2$, in which the two $\mathrm{Cu}$ (II) centers remained in the same oxidation state but the ligand was oxidized to the radical cation. The observed doublet spin indicated an antiferromagnetic interaction between the monoradical $[74]^{+}$and the $\mathrm{Cu}$ (II) center. Moreover, the dication $\mathbf{7 4}\left(\mathrm{BF}_{4}\right)_{2}$ was found to be a $\pi$-diradical, in which the two $\mathrm{Cu}(\mathrm{II})$ centers remained in the same oxidation state as determined by XAFS. X-ray diffraction analysis revealed the similar twisted structure of $\mathbf{7 4}\left(\mathbf{B F}_{4}\right)_{2}$, which was feasible for ferromagnetic coupling of the two $\mathrm{Cu}(\mathrm{II})$ centers. However, $\mathbf{7 4}\left(\mathbf{B F}_{\mathbf{4}}\right)_{2}$ exhibited

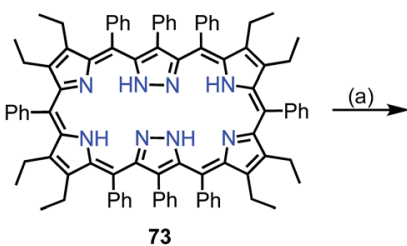

73

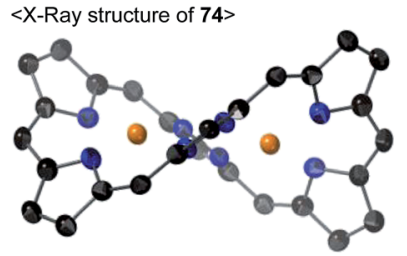

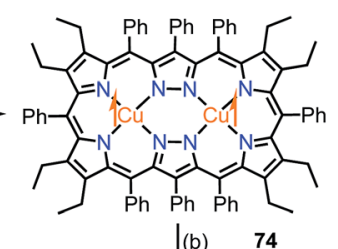

$\downarrow$ (b)

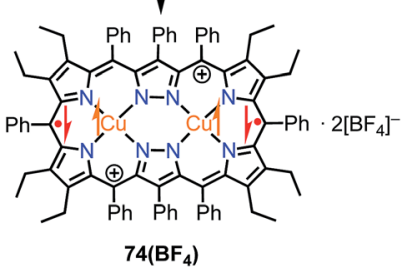

Fig. 23 Siamese-twin porphyrin and its $\mathrm{Cu}(\mathrm{II})$ complexes. (a) 4 equiv. $\mathrm{Cu}(\mathrm{OAC})_{2} \cdot \mathrm{H}_{2} \mathrm{O}, \mathrm{CH}_{2} \mathrm{Cl}_{2} / \mathrm{MeOH}$, rt, overnight, 29\%; (b) 2 equiv. $\mathrm{AgBF}_{4}$ in $\mathrm{EtNO}{ }_{2}, \mathrm{CH}_{2} \mathrm{Cl}_{2}, \mathrm{rt}, 97 \%$. diamagnetic $(S=0)$ character. The authors suggested the ligand diradical character of $[\mathbf{7 4}]^{2+}$, which coupled strongly with the $\mathrm{Cu}$ (II) center to cancel out the net spin. The $\pi$-diradical character of $[74]^{2+}$ may arise from the non-Kekule nature of the dication owing to cross-conjugation between the pyrazole rings.

\subsection{Magnetic interaction with the central metal}

When a porphyrinoid $\pi$-radical has a paramagnetic metal in the central cavity, a magnetic interaction between the porphyrin radical ligand and the paramagnetic metal center is possible. Earlier, this was examined for the $\pi$-radical cation of meso-tetraphenyl $\mathrm{Cu}(\mathrm{II})$ porphyrin $75^{+}$, which was characterized as paramagnetic $(S=1$ or $S=1 / 2,1 / 2)$ in solution but diamagnetic $(S=0)$ in the solid state. ${ }^{62,63}$ Orthogonality between the $\mathrm{a}_{\mathrm{u}}$ SOMO of the ligand and the $\mathrm{d}_{x_{2}-y_{2}}$ orbitals of $\mathrm{Cu}$ (II) has been assigned as responsible for the ferromagnetic interaction. Therefore, the ferromagnetic interaction was observed in solution owing to the planar structure and the resulting strict orthogonality, but a slight structural distortion in the solid state gave rise to an antiferromagnetic interaction. It should be noted that other metalloporphyrin radical ions such as $76^{+}$and $77^{+}$ have also been investigated as model compounds of compound I (Fig. 24). ${ }^{64}$

Square-planar Ni(II) porphyrins are usually diamagnetic (lowspin, $S=0$ ), but become paramagnetic (high-spin, $S=1$ ) upon the coordination of an additional ligand (Fig. 25). ${ }^{65}$ The orbitals responsible for the spin of high-spin $\mathrm{Ni}$ (II) have $\sigma$-character, and the $\pi$-radicals should be orthogonal, which leads to a ferromagnetic interaction as in the case of $\mathrm{Cu}(\mathrm{II})$ porphyrins. Balch et al. reported that the $\beta$-octaethylporphyrin $\mathrm{Ni}$ (II) complex $21 \mathrm{Ni}$ existed as a doublet species $(S=1 / 2)$ as a consequence of an antiferromagnetic interaction between the high-spin Ni(II) atom and the $\pi$-radical. On the other hand, Osuka et al. reported a strong ferromagnetic interaction in the meso-pentafluorophenylporphyrin Ni(II) complex 78Ni. ${ }^{66}$ The authors suggested that the balance of magnetic interactions between the central metal and the ligand radical was likely to be sensitive, so that a very small structural distortion could alter the magnetic interaction.

\section{Kekulé/non-Kekulé radicals}

Delocalized radicals can be divided into Kekulé and non-Kekulé molecules. ${ }^{67}$ In most Kekule-type diradicals, the loss of bondformation energy due to the presence of two unpaired electrons is compensated by a gain in aromatic stabilization

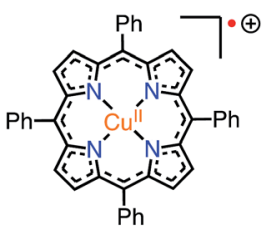

$75^{+}$

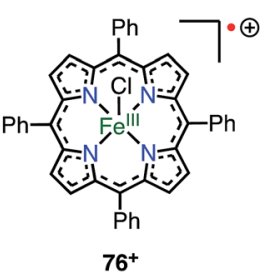

$76^{+}$

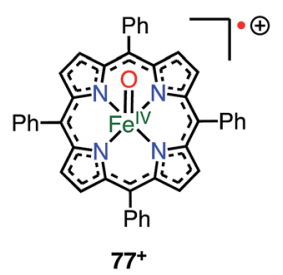

$77^{+}$
Fig. 24 Radical cations of metalloporphyrins. 

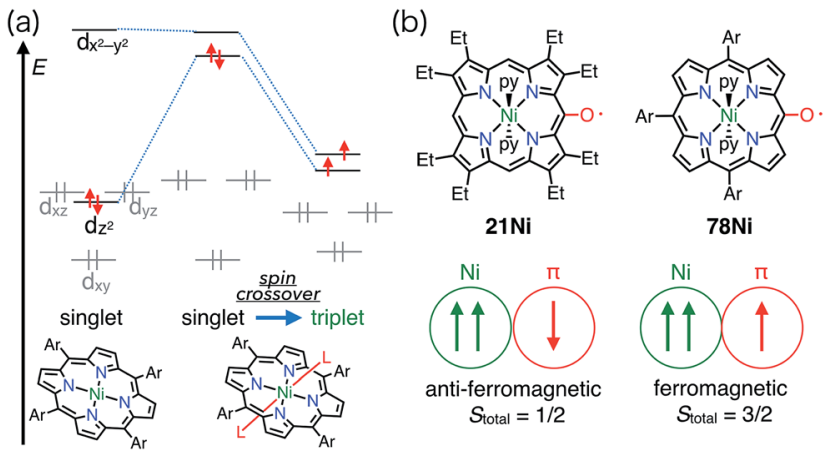

Fig. 25 (a) Coordination-induced spin crossover of $\mathrm{Ni}\left({ }^{\prime \prime}\right)$ center. (b) OEP and 10,15,20-triarylporphyrin meso-oxy radicals and their magnetic interaction with the $\mathrm{Ni}(॥)$ center. $\mathrm{Ar}=$ pentafluorophenyl.

energy. ${ }^{68}$ On the other hand, non-Kekule radicals have structures that cannot be drawn as a closed-shell form.

\subsection{Quinonoidal porphyrinoids}

5,10- and 5,15-quinonoidal porphyrins, which can be drawn as diradicals with the retention of the macrocyclic aromatic conjugation circuit, are also promising candidates for obtaining stable diradical species. However, the macrocyclic aromatic stabilization energy of porphyrin seems relatively small in comparison with the bond dissociation energy. ${ }^{4}$ Consequently, the closed-shell quinonoidal electronic structure is more favorable, as seen in 34 and 79-82 (Fig. 26)..$^{33,69-71}$ These quinonoidal porphyrinoids exhibit unique optical and electrochemical properties owing to decreased HOMO-LUMO gaps and perturbed aromaticity.

Osuka et al. prepared a series of 5,15-bis(3,5-di-tert-butyl-4hydroxyphenyl-oligothienylene)-substituted porphyrins 83_n and [26] hexaphyrins 84_n (Fig. 27). ${ }^{72}$ Whereas 83_0, 84_0, and 84_1 exhibited sharp ${ }^{1} \mathrm{H}$ NMR signals corresponding to a closed-shell quinonoidal structure, 83_1 and 84_2 remained silent or displayed broad signals even at low temperatures. Theoretical calculations at the UHF/6-31G*//B3LYP/6-31G* level revealed large diradical indices of 0.99 for $83 \_1$ and 0.85 for 84_2. Compound 83_1 was sufficiently stable for isolation but sensitive to air and moisture. This chemical instability implied

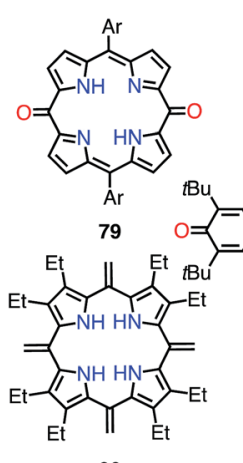

80

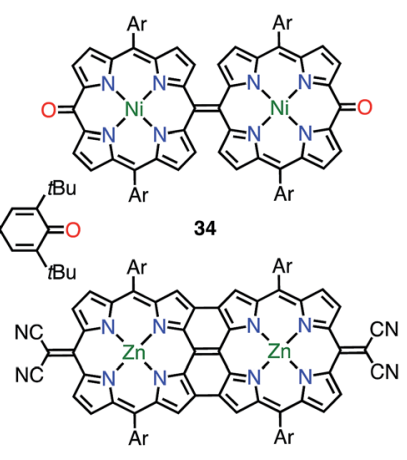

82
Fig. 26 Quinonoidal porphyrins.
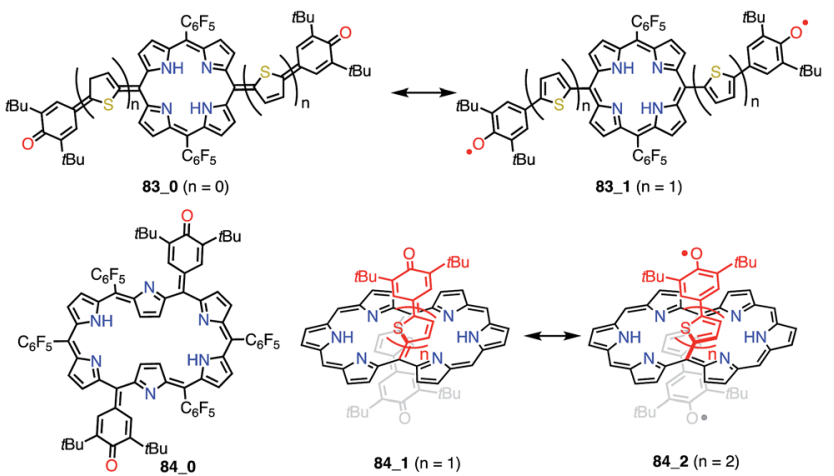

Fig. 27 Thienylquinonoidal porphyrins and hexaphyrins. The meso$\mathrm{C}_{6} \mathrm{~F}_{5}$ groups in 84_1 and 84_2 are omitted for clarity.

that the spin was less delocalized over the porphyrin core. On the other hand, 84_2 was highly stable, which was presumably due to effective spin delocalization over the hexaphyrin core, as indicated by DFT calculations. Judging from the exchange integral $\left(J / k_{\mathrm{B}}=-33 \mathrm{~K}\right.$ for 83_1 and $J / k_{\mathrm{B}}=-940 \mathrm{~K}$ for 84 $\left.\_2\right)$, the interaction between the two phenoxy radicals was slight in 83_1 in comparison with that in 84_2, which also suggested that 83_1 was less conjugated. The strong antiferromagnetic interaction in 84_2 was presumably due to through-space spin-spin interactions, which are inaccessible for their porphyrin counterparts, as well as through-bond conjugation.

\subsection{2,18-Doubly linked corrole dimer}

Shinokubo et al. synthesized the 2,18-doubly linked corrole dimer 85 with a cyclooctatetraene (COT) moiety in the center via oxidative fusion of a 2,2'-linked corrole dimer (Fig. 28). ${ }^{73}$ 85 was quantitatively oxidized with DDQ to give 86 , and the metal complexes $85 \mathrm{Co}$ and $86 \mathrm{Zn}$ were also prepared. Whereas 85 and 85Co displayed absorption spectra that were typical of aromatic corroles, 86 and $\mathbf{8 6 Z n}$ exhibited largely perturbed spectra that extended to $1700 \mathrm{~nm}$. 86Zn was NMR-silent but EPR-active and displayed a sharp signal at $g=2.0053 .86$ and 86Zn were characterized as singlet diradicals. A SQUID study
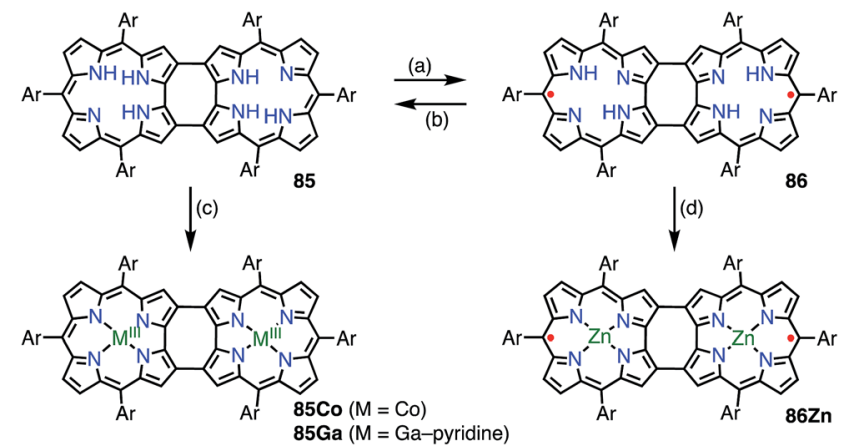

Fig. 28 2,18-Doubly linked corrole dimers. (a) 5 equiv. DDQ, toluene, rt, 2 h, 83\%; (b) $\mathrm{NaBH}_{4}$, THF, rt, quant.; (c) 5 equiv. $\mathrm{Co}(\mathrm{OAc})_{2}, 7.8$ equiv. $\mathrm{PPh}_{3}, \mathrm{EtOH}, \mathrm{rt}, 1.5 \mathrm{~h}, 78 \%$; (d) sat. $\mathrm{Zn}(\mathrm{OAc})_{2}$ in $\mathrm{EtOH}, \mathrm{CHCl}_{3}, \mathrm{rt}, 1 \mathrm{~h}, 54 \%$. $\mathrm{Ar}=$ pentafluorophenyl. 
of $86 \mathrm{Zn}$ revealed an antiferromagnetic interaction with $J / k_{\mathrm{B}}=$ $-470 \mathrm{~K}$.

It is worth noting that the triply linked corrole dimer 87 also possessed a dimeric structure consisting of inner $2 \mathrm{NH}$ corroles, but 87 was a closed-shell molecule with a short $\mathrm{C} 10-\mathrm{C} 10^{\prime}$ distance of $1.389 \AA$ (Fig. 29). ${ }^{74 a}$ Recently, Gross et al. reported the synthesis and electronic structure of $85 \mathbf{G a} .{ }^{74 b}$ The authors showed that the HOMO-1 of 85Ga, which may correspond to the SOMO of the diradical 86, had a very low spin density on C2 and C18, but a large coefficient on C15. The small extent of the overlap of the SOMOs may be the origin of the diradical character of 86 and $86 \mathrm{Zn}$.

\subsection{Phenalenyl-fused porphyrins}

Phenalenyl is a very important stable organic $\pi$-radical and has been extensively studied from both experimental and theoretical viewpoints. ${ }^{75} \mathrm{Wu}$ et al. prepared precursors of the monoand bis-phenalenyl-fused porphyrins 88 and 90 via an intramolecular Friedel-Crafts reaction. ${ }^{76}$ The authors concluded that the subsequent oxidation of $\mathbf{8 8}$ and $\mathbf{9 0}$ led to the formation of $\mathbf{8 9}$ and 91, respectively (Fig. 30). Compound 89 was characterized as a closed-shell chromophore with a sharp ${ }^{1} \mathrm{H}$ NMR spectrum and a small diradical index of 0.06. Unfortunately, 91 was unstable under ambient conditions and gave the $\beta$-oxidized products 92 and 93 . The EPR signal of 91 displayed clear hyperfine coupling with two sets of protons, which was consistent with the proposed structure. DFT calculations suggested that 91 was a ground-state triplet diradical with $J / k_{\mathrm{B}} \approx$ $+1800 \mathrm{~K}$, although no experimental evidence in support of the

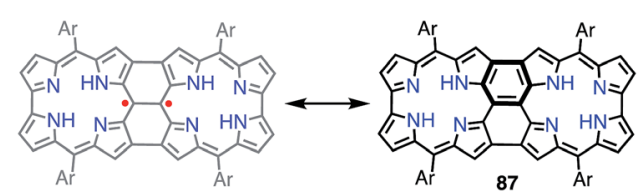

Fig. 29 Triply linked corrole dimer. Ar = pentafluorophenyl.

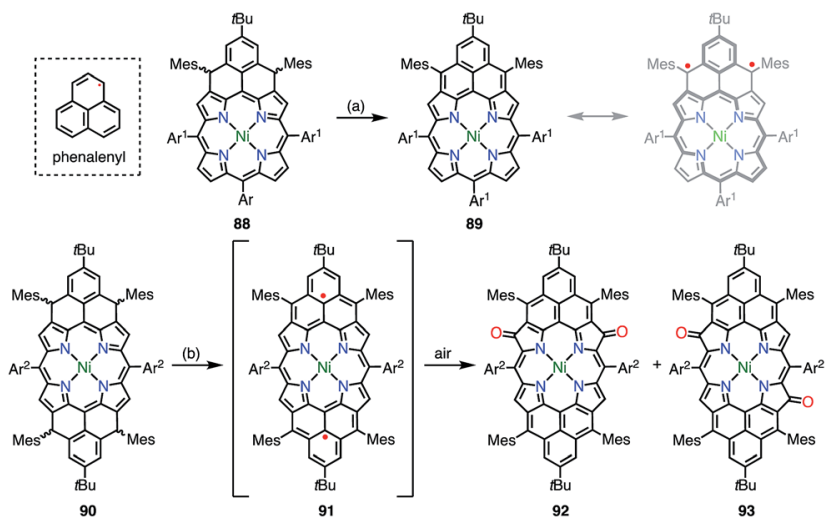

Fig. 30 Peripherally phenalenyl-fused porphyrins. Reagents and conditions: (a) 2 equiv. NIS, $\mathrm{CH}_{2} \mathrm{Cl}_{2}, \mathrm{rt}, 5 \mathrm{~min}, 49 \%$; (b) 2 equiv. $p$ chloranil, $\mathrm{CH}_{2} \mathrm{Cl}_{2}, \mathrm{rt}, 10 \mathrm{~min} .92$ and 93 were obtained after exposure to air for $3.5 \mathrm{~h}, 20 \%$ for $92,39 \%$ for 93 . $\mathrm{Ar}^{1}=4$-tert-butylphenyl, $\mathrm{Ar}^{2}=$ 3,5-di-tert-butylphenyl. spin and oxidation state of $\mathbf{9 1}$ was reported. It is noteworthy that 91 formally bears two radicals on the $\mathrm{sp}^{2}$-carbon atoms attached to the meso-positions, but 91 cannot be drawn as a closed-shell structure owing to the externally fused conjugation circuit.

Osuka et al. also reported the similar peri-dinaphthoporphyrin $94,{ }^{77}$ which comprises a partial structure of 91 and porphyrin tapes. ${ }^{78} 94$ was characterized as a closed-shell antiaromatic molecule (Fig. 31). Thompson et al. also prepared the bis-phenalenyl-fused porphyrin 95 by oxidative fusion followed by thermal dehydroaromatization. ${ }^{79}$ However, 95 was a closed-shell molecule with a calculated diradical index of $<3 \%$. The clear difference between $\mathbf{9 1}, \mathbf{9 4}$ and $\mathbf{9 5}$ is indicative that the design of the conjugation circuit is of great importance in producing a diradical.

\subsection{Thermally induced radical character}

Chmielewski et al. reported the synthesis of the pyrimidinenorcorrole dimer 99 via a unique ring expansion reaction of Ni(II)-norcorrole 96 (Fig. 32). ${ }^{80} 99$ existed in equilibrium with its homolysis product $\mathbf{1 0 0}$ in toluene, which was proved by VT-EPR measurements and measurements of the temperature dependence of absorption. The population of $\mathbf{1 0 0}$ was estimated from VT-NMR measurements to be $12 \%$ at $300 \mathrm{~K}$ and almost $90 \%$ at $373 \mathrm{~K}$. This process was reversible and reproducible in the open air, which indicated both the thermal stability and the chemical stability of $\mathbf{1 0 0}$. Surprisingly, the dimerization of $\mathbf{1 0 0}$ was completely regioselective, whereas the spin density of $\mathbf{1 0 0}$ was fairly delocalized, as evidenced by both the hyperfine coupling constants observed in the EPR spectrum and DFT calculations. Moreover, 99 was further oxidized in DMF (even degassed and under $\mathrm{N}_{2}$ ) to give 101. The oxidation of 99 to 101 also proceeded in toluene with the aid of a catalyst. X-ray diffraction analysis revealed a molecular twist around the C3C3 ${ }^{\prime}$ bond with a dihedral angle of $44^{\circ}$ and a relatively short C-C distance of $1.437 \AA$. In the solid state, a small amount of a paramagnetic species was observed $(6 \%$ on the assumption of a triplet species) by a SQUID study. The EPR signal of 101 in the solid state displayed a fine structure with a zero-field splitting parameter of $D=20 \mathrm{mT}$, which is typical of triplet species. A VTNMR study of the spin-lattice relaxation time $\left(T_{1}\right)$ revealed that $T_{1}$ was shorter at $300 \mathrm{~K}(0.04-0.5 \mathrm{~s})$ in comparison with its value

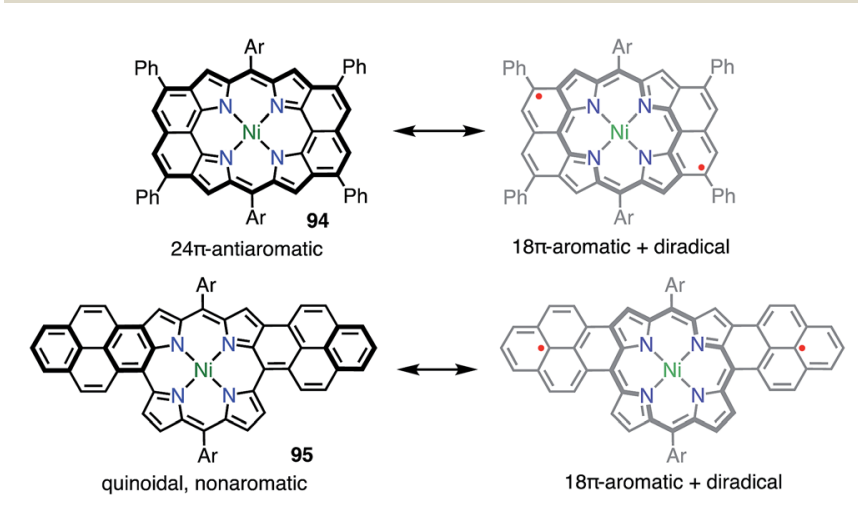

Fig. 31 Peripherally fused porphyrins. Ar = 3,5-di-tert-butylphenyl. 

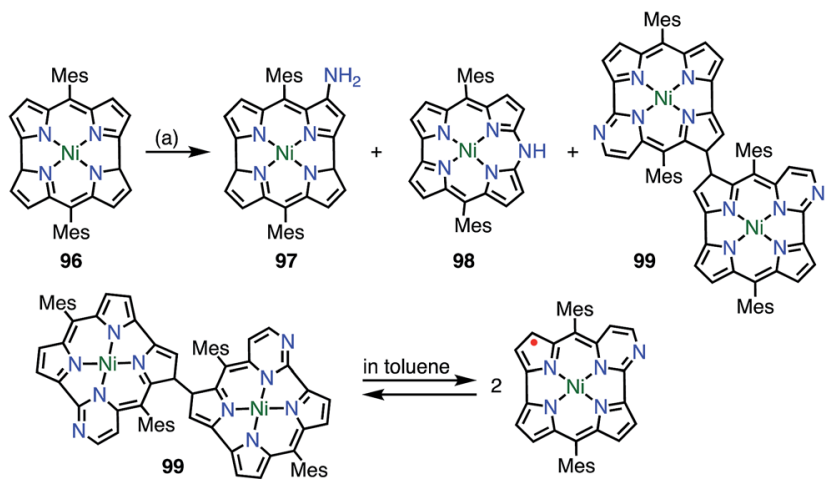

(b)
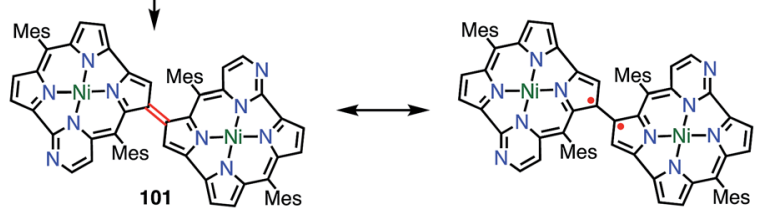

Fig. 32 Series of pyrimidinenorcorrole derivatives. (a) 12.5 equiv. 4Amino-4H-1,2,4-triazole, 20 equiv. $\mathrm{NaOH}$, THF, reflux, 2 h, 8.6\% for $97,28.8 \%$ for $98,3.3 \%$ for $99,32.2 \%$ for 100 ; (b) degassed DMF, $N_{2}$, $80{ }^{\circ} \mathrm{C}, 30 \mathrm{~min}, 98 \%$.

at $183 \mathrm{~K}\left(T_{1}>1 \mathrm{~s}\right)$, which indicated thermally enhanced paramagnetic character. Rotation around the $\mathrm{C} 3-\mathrm{C} 3^{\prime}$ bond was also observed in the form of averaging of the signals due to the meso-mesityl groups. The authors proposed that the population of the paramagnetic form was higher and/or chemical exchange between the forms was faster upon heating. These phenomena were further supported by quantum calculations that showed that the $\mathrm{S}-\mathrm{T}$ gap was dependent on the dihedral angle.

$\mathrm{Wu}$ et al. also proposed the thermally induced diradical characters of the 5,15-bis(9-fluorenylidene)porphyrin 102 and its Ni complex 102Ni (Fig. 33). ${ }^{81}$ Both 102 and 102Ni adopted quinonoidal structures in the single-crystal state with distortions due to steric hindrance by the fluorenyl groups. X-ray analysis revealed the highly bent structure of $\mathbf{1 0 2}$ due to steric

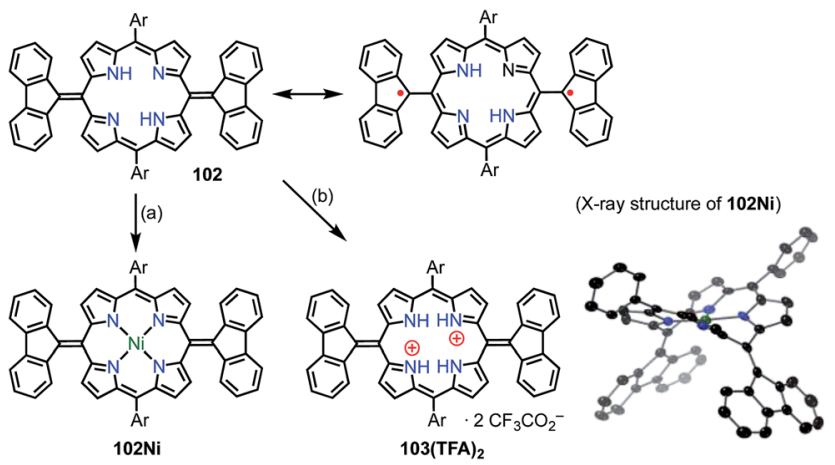

Fig. 33 5,15-Bis(9-fluorenyl)porphyrins and $\mathrm{X}$-ray crystal structure of 102Ni. (a) 10 equiv. $\mathrm{Ni}(\mathrm{OAc})_{2} \cdot 4 \mathrm{H}_{2} \mathrm{O}$, toluene, $120^{\circ} \mathrm{C}, 5 \mathrm{~h}$, quant.; (b) 2 equiv. $\mathrm{CF}_{3} \mathrm{CO}_{2} \mathrm{H}, \mathrm{CH}_{2} \mathrm{Cl}_{2},<10$ min, quant. $\mathrm{Ar}=3,5$-di-tert-butylphenyl. Hydrogen atoms and tert-butyl groups in the crystal structure of $102 \mathrm{Ni}$ are omitted for clarity. repulsion between the $\beta$-proton and the fluorenyl group with a short $\mathrm{C}_{\text {meso }}-\mathrm{C}_{\text {fluorenyl }}$ bond length of 1.35-1.37 $\AA$. A VT-NMR study detected signal broadening at high temperatures, which indicated the structural flexibility of 102 and 102Ni. 102Ni exhibited signal broadening at lower temperatures than 102, which has been interpreted in terms of the conformational flexibility of $\mathbf{1 0 2 N i}$, despite its metalation. A SQUID study of $\mathbf{1 0 2}$ and 102Ni revealed unusual open hysteresis loops for net magnetization. ${ }^{82}$ The estimated value of $\Delta E_{\mathrm{ST}}$ was higher in 102 than in 102Ni, which was consistent with the VT-NMR results. From these results and DFT calculations, the authors proposed that the diradical character was triggered by a thermally induced "butterfly-like" structural change. Protonation also altered the diradical character of $\mathbf{1 0 2}$. For example, protonation of 102 gave 103(TFA) $)_{2}$ in quantitative yield, which exhibited sharp NMR signals even at high temperatures, which indicated closed-shell character.

In the case of 102, structural flexibility induced the diradical character. Very recently, Osuka et al. reported a contrasting system in which diradical character was enhanced via structural rigidification. ${ }^{83}$ As shown above, the 5,5'-linked 15,15'-dioxo-Ni(II)-diporphyrin 34 was known to be a closedshell quinonoid with a distorted structure. It was considered that the replacement of the central metal would lead to changes in the structure and thus magnetic interactions. In fact, the Ni(II) complex 104Ni was a closed-shell quinonoid similar to 34, but the Zn(II) complex 105ZnIm was found to be a stable diradical (Fig. 34). X-ray diffraction analysis of 105ZnIm showed a perpendicular structure consisting of two highly planar porphyrin segments with a dihedral angle of $71^{\circ}$. The C5-C5' bond length (1.492 Å) clearly indicated singlebond character. These structural features indicated a diradical electronic state, which was supported by the silent ${ }^{1} \mathrm{H}$ NMR spectrum, the active EPR spectrum, magnetism detected by SQUID experiments, a broad absorption tail extending to $1800 \mathrm{~nm}$, and DFT calculations. Moreover, the free base $\mathbf{1 0 4}_{\mathbf{2}}$ was found to exist as an equilibrium mixture of the closedshell quinonoid $\mathbf{1 0 4 H}_{2}$ and the diradical $\mathbf{1 0 5}_{\mathbf{2}}\left(\mathbf{1 0 4 \mathbf { H } _ { 2 }} /\right.$ $\mathbf{1 0 5 H}_{\mathbf{2}}=81 / 19$ in toluene at room temperature), as evidenced by VT-EPR and VT-NMR studies. The contribution of $\mathbf{1 0 5} \mathbf{H}_{\mathbf{2}}$ increased at high temperatures.

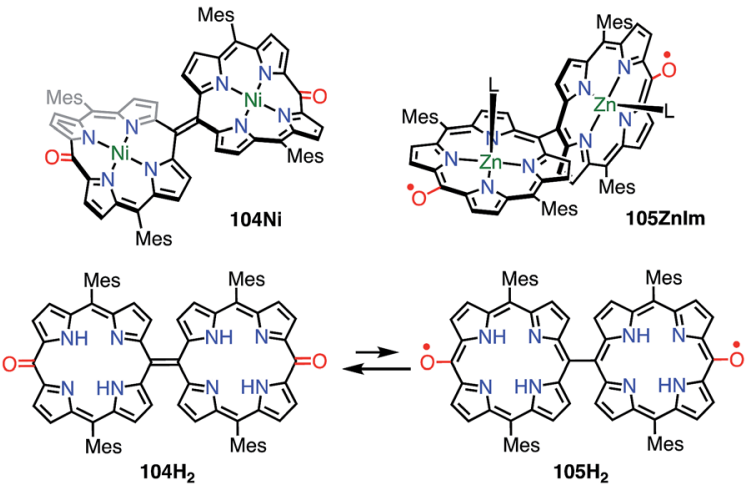

Fig. 34 5,5'-Linked 15,15'-dioxodiporphyrins. $L=N$-methylimidazole. 


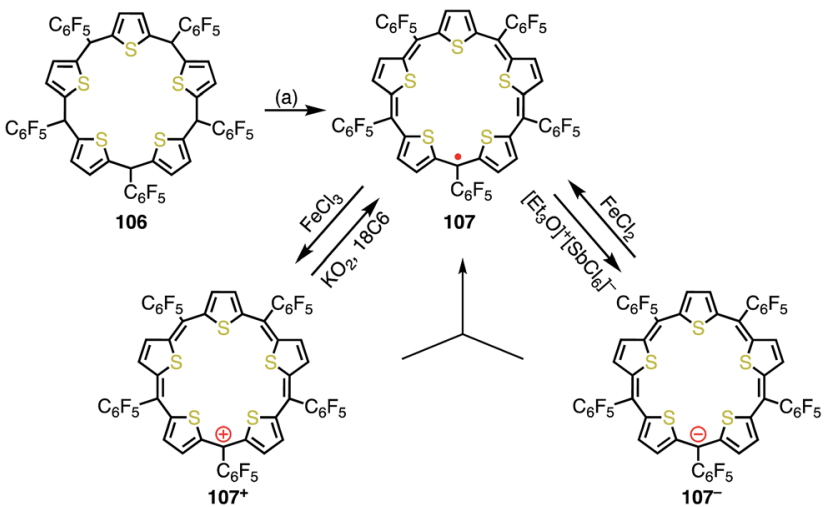

Fig. 35 Synthesis and redox behavior of pentathiapentaphyrin 107. (a) $\mathrm{FeCl}_{3}, \mathrm{CH}_{2} \mathrm{Cl}_{2}, \mathrm{rt}, 1 \mathrm{~h}$, then triethylamine, rt, 38\%.

\section{Other example}

\subsection{Pentathiapentaphyrin}

Anand et al. reported the synthesis of pentathiapentaphyrin(1.1.1.1.1) $\mathbf{1 0 7},{ }^{84}$ which cannot be drawn as a neutral closed-shell form without an unpaired electron, in a similar way to the corrole radical 72 (Fig. 35). X-ray crystallographic analysis revealed its planar structure, which was suitable for spin delocalization. In fact, 107 displayed high stability towards air and moisture. The radical 107 could be reversibly oxidized/reduced to give the $24 \pi$ anti-aromatic cation $107^{+}$and the $26 \pi$ aromatic anion $107^{-}$, respectively. The mixing of $\mathbf{1 0 7}^{+}$and $107^{-}$formed 107, which indicated the high tendency to comproportionation and thus the high stability of $\mathbf{1 0 7}$.

\section{Conclusion and perspectives}

We reviewed porphyrinoid-based stable radicals mainly from the viewpoints of radical structure and stability. Early research focused on porphyrinoid-based radicals as important reaction intermediates in biochemistry. Recently, interest has been shifting to the investigation of functional materials based on stable radicals. The remarkable stability of porphyrinoid radicals is mainly due to effective spin delocalization (thermal stabilization). However, in some cases steric protection at positions where relatively high spin density is localized (kinetic stabilization) is necessary for chemical stability. The effective spin delocalization ability of porphyrinoids can be attributed to their unique structural and electronic flexibilities. Reflecting their delocalized $\pi$-radical characters, these radicals generally exhibit unique properties such as NIR absorption bands, magnetic properties, and small redox gaps.

There is ample room for further functionalization of stable porphyrinoids by taking advantage of their stability as well as properties such as light-harvesting functions, structural flexibility, and metal-coordinating ability. Owing to their chemical stability and unique properties, porphyrinoid-based radicals are promising candidates for future applications. The precise alignment of radicals in the solid and liquid-crystalline phases is required to achieve effective bulk properties, but general guidelines for the design of packing structures have not yet been established. Most of the stable radicals that have been synthesized so far are $[4 n+1] \pi$-species, and the stabilization of $[4 n+3] \pi$ electronic radicals (and radical anions) still remains a challenging topic. The investigation of general strategies for stabilizing such electron-rich $\pi$-radicals will be important, because it will help in the creation of novel functional molecules. A recent study revealed the triplet Baird-type aromaticity of an internally dithienothiophene-bridged [34]octaphyrin dication. ${ }^{85}$ The excited-state dynamics of porphyrinoid-based radicals are also of great interest.

In addition, porphyrinoids may be promising for stabilizing radical-related unstable chemical species such as carbenes, nitrenes and other reactive species. ${ }^{\mathbf{8 6 7}}$ Related studies are actively in progress in our laboratory, and we hope to report their results in the near future.

\section{Conflicts of interest}

There are no conflicts to declare.

\section{Acknowledgements}

We thank JSPS KAKENHI grant no. 25220802 and 16K13952 for supporting our stable radical chemistry. D. S. acknowledges a JSPS fellowship for young scientists.

\section{Notes and references}

1 (a) Handbook of Porphyrin Science, ed. K. M. Kadish, K. M. Smith and R. Guilard, World Scientific Publishing, Singapore, 2010, vol. 1-25; (b) The Porphyrin Handbook, ed. K. M. Kadish, K. M. Smith and R. Guilard, Academic Press, San Diego, 2000, vol. 1-10; (c) A. Osuka, E. Tsurumaki and T. Tanaka, Bull. Chem. Soc. Jpn., 2011, 84, 679; (d) C. G. Claessens, D. González-Rodríguez, M. S. RodríguezMorgade, A. Medina and T. Torres, Chem. Rev., 2014, 114, 2192; (e) S. Shimizu, Chem. Rev., 2017, 117, 2730; (f) S. Saito and A. Osuka, Angew. Chem., Int. Ed., 2011, 50, 4342; $(g)$ A. Osuka and S. Saito, Chem. Commun., 2011, 47, 4330; (h) T. Tanaka and A. Osuka, Chem. Rev., 2017, 117, 2584; (i) B. Szyszko, M. J. Białek, E. Pacholska-Dudziak and L. Latos-Grażyński, Chem. Rev., 2017, 117, 2839.

2 (a) J. P. McEvoy and G. W. Brudvig, Chem. Rev., 2006, 106, 4455; (b) P. Hlavica, Eur. J. Biochem., 2004, 271, 4335.

3 (a) Y. Yamamoto, Y. Hirata, M. Kodama, T. Yamaguchi, S. Matsukawa, K. Akiba, D. Hashizume, F. Iwasaki, A. Muranaka, M. Uchiyama, P. Chen, K. M. Kadish and N. Kobayashi, J. Am. Chem. Soc., 2010, 132, 12627; (b) S. Sugawara, Y. Hirata, S. Kojima, Y. Yamamoto, E. Miyazaki, K. Takimiya, S. Matsukawa, D. Hashizume, J. Mack, N. Kobayashi, Z. Fu, K. M. Kadish, Y. M. Sung, K. S. Kim and D. Kim, Chem.-Eur. J., 2012, 18, 3566; (c) M. Pohl, H. Schmisckler, J. Lex and E. Vogel, Angew. Chem., Int. Ed. Engl., 1991, 31, 1693; (d) C. Liu, D.-M. Shen and Q.-Y. Chen, J. Am. Chem. Soc., 2007, 129, 5814. 
4 (a) J. Aihara, J. Phys. Chem. A, 2008, 112, 5305; (b) J. L. Wu, I. Fernandez and P. v. R. Schleyer, J. Am. Chem. Soc., 2013, 135, 315; (c) J. Aihara and H. Horibe, Org. Biomol. Chem., 2009, 7, 1939; (d) M. Makino and J. Aihara, J. Phys. Chem. A, 2012, 116, 8074.

5 (a) T. Asakura, J. S. Leigh Jr., H. R. Drott, T. Yonetani and B. Chance, Proc. Natl. Acad. Sci. U. S. A., 1971, 68, 861; (b) M. H. Rakowski, K. M. More, A. V. Kulikov, G. R. Eaton and S. S. Eaton, J. Am. Chem. Soc., 1995, 117, 2049.

6 T. T. H. Tram, Y.-R. Chang, T. K. A. Hoang, M.-Y. Kuo and Y. O. Su, J. Phys. Chem. A, 2016, 120, 5511.

7 J. Rittle and M. T. Green, Science, 2010, 330, 933.

8 (a) T. Satoh, M. Minoura, H. Nakano, K. Furukawa and Y. Matano, Angew. Chem., Int. Ed., 2016, 55, 2235; (b) K. Sudoh, T. Satoh, T. Amaya, K. Furukawa, M. Minoura, H. Nakano and Y. Matano, Chem.-Eur. J., 2017, 23, 16364.

9 A. Yamaji, H. Tsurugi, Y. Miyake, K. Mashima and H. Shinokubo, Chem.-Eur. J., 2016, 22, 3956.

10 N. Fukui, W. Cha, D. Shimizu, J. Oh, K. Furukawa, H. Yorimitsu, D. Kim and A. Osuka, Chem. Sci., 2017, 8, 189. 11 N. Fukui, H. Yorimitsu and A. Osuka, Chem.-Eur. J., 2016, 22, 18476.

12 J. Mack and M. J. Stillman, J. Porphyrins Phthalocyanines, 2001, 5, 67.

13 T. Koide, G. Kashiwazaki, M. Suzuki, K. Furukawa, M.-C. Yoon, S. Cho, D. Kim and A. Osuka, Angew. Chem., Int. Ed., 2008, 47, 9661.

14 H. Rath, S. Tokuji, N. Aratani, K. Furukawa, J. M. Lim, D. Kim, H. Shinokubo and A. Osuka, Angew. Chem., Int. Ed., 2010, 49, 1489.

15 T. Yoshida, W. Zhou, T. Furuyama, D. B. Leznoff and N. Kobayashi, J. Am. Chem. Soc., 2015, 137, 9258.

16 J. Rawson, P. J. Angiolillo and M. J. Therien, Proc. Natl. Acad. Sci. U. S. A., 2015, 112, 13779.

17 M. D. Peeks, C. E. Tait, P. Neuhaus, G. M. Fischer, M. Hoffmann, R. Haver, A. Cnossen, J. R. Hammer, C. R. Timmel and H. L. Anderson, J. Am. Chem. Soc., 2017, 139, 10461.

18 (a) T. Yoshida, M. Noguchi, G. Kikuchi and S. Sano, J. Biochem., 1981, 90, 125; (b) S. Sano, T. Sano, I. Morishima, Y. Shiro and Y. Maeda, Proc. Natl. Acad. Sci. U. S. A., 1986, 83, 531; (c) A. Wilks and P. R. O. de Montellano, J. Biol. Chem., 1993, 268, 22357; (d) A. Gossauer, Chimia, 1994, 48, 352.

19 K. M. Matera, S. Takahashi, H. Fujii, H. Zhou, K. Ishikawa, T. Yoshimura, D. L. Rousseau, T. Yoshida and M. IkedaSaito, J. Biol. Chem., 1996, 271, 6618.

20 R. Bonnett, M. J. Dimsdale and K. D. Sales, Chem. Commun., $1970,962$.

21 A. L. Balch, B. C. Noll and E. P. Zovinka, J. Am. Chem. Soc., 1992, 114, 3380.

22 J.-H. Fuhrhop, S. Besecke, J. Subramanian, C. Mengersen and D. Riesner, J. Am. Chem. Soc., 1975, 97, 7141.

23 A. L. Balch, Coord. Chem. Rev., 2000, 200-202, 349.

24 A. L. Balch, B. C. Noll, S. L. Phillips, S. M. Reid and E. P. Zovinka, Inorg. Chem., 1993, 32, 4730.
25 R. G. Khoury, L. Jaquinod, A. M. Shachter, N. Y. Nelson and K. M. Smith, Chem. Commun., 1997, 215.

26 R. G. Khoury, L. Jaquinod, R. Paolesse and K. M. Smith, Tetrahedron, 1999, 55, 6713.

27 T. Koide, K. Furukawa, H. Shinokubo, J.-Y. Shin, K. S. Kim, D. Kim and A. Osuka, J. Am. Chem. Soc., 2010, 132, 7246.

28 M. Ishida, J.-Y. Shin, J. M. Lim, B. S. Lee, M.-C. Yoon, T. Koide, J. L. Sessler, A. Osuka and D. Kim, J. Am. Chem. Soc., 2011, 133, 15533.

29 D. Shimizu, J. Oh, K. Furukawa, D. Kim and A. Osuka, Angew. Chem., Int. Ed., 2015, 54, 6613.

30 D. Shimizu, J. Oh, K. Furukawa, D. Kim and A. Osuka, J. Am. Chem. Soc., 2015, 137, 15584.

31 L. J. Esdaile, M. O. Senge and D. P. Arnold, Partial formation of similar meso-oxy radical had been suggested before, but isolation or characterization had not been achieved, Chem. Commun., 2006, 4192.

32 (a) H. Song, R. D. Orosz, C. A. Reed and R. Scheidt, Inorg. Chem., 1990, 29, 4274; (b) W. R. Scheidt, K. E. BrancatoBuentello, H. Song, K. V. Reddy and B. Cheng, Inorg. Chem., 1996, 35, 7500; (c) K. M. Barkigia, M. W. Renner and J. Fajer, J. Phys. Chem. B, 1997, 101, 8398.

33 L. J. Esdaile, L. Rintoul, M. S. Goh, K. Merahi, N. Parizel, R. M. Wellard, S. Choua and D. P. Arnold, Chem.-Eur. J., 2016, 22, 3403.

34 K. Fujimoto, J. Oh, H. Yorimitsu, D. Kim and A. Osuka, Angew. Chem., Int. Ed., 2016, 55, 3196.

35 N. Fukui, W.-Y. Cha, S. Lee, S. Tokuji, D. Kim, H. Yorimitsu and A. Osuka, Angew. Chem., Int. Ed., 2013, 52, 9728.

36 K. Kato, W. Cha, J. Oh, K. Furukawa, H. Yorimitsu, D. Kim and A. Osuka, Angew. Chem., Int. Ed., 2016, 55, 8711.

37 A. Wakamiya and S. Yamaguchi, Bull. Chem. Soc. Jpn., 2015, 88, 1357.

38 K. Kato, K. Furukawa, T. Mori and A. Osuka, Chem.-Eur. J., 2018, 24, 572.

39 R. G. Hicks, Org. Biomol. Chem., 2007, 5, 1321.

40 D. Shimizu, S. K. Lee, D. Kim and A. Osuka, Chem.-Asian J., 2016, 11, 2946.

41 D. Shimizu, K. Furukawa and A. Osuka, Angew. Chem., Int. Ed., 2017, 56, 7435.

42 (a) P. J. Chirik, Inorg. Chem., 2011, 50, 9737; (b) V. Lyaskovskyy and B. de Bruin, ACS Catal., 2012, 2, 270.

43 B. Sridevi, S. Jeyaprakash, R. Rao, T. K. Chandrashekar, U. Englich and K. Ruhlandt-Senge, Inorg. Chem., 2000, 39, 3669.

44 Y. Hisamune, K. Nishimura, K. Isakari, M. Ishida, S. Mori, S. Karasawa, T. Kato, S. Lee, D. Kim and H. Furuta, Angew. Chem., Int. Ed., 2015, 54, 7323.

45 X.-S. Ke, Y. Hong, P. Tu, Q. He, V. M. Lynch, D. Kim and J. L. Sessler, J. Am. Chem. Soc., 2007, 139, 15232.

46 Y. Tanaka, T. Yoneda, K. Furukawa, T. Koide, H. Mori, T. Tanaka, H. Shinokubo and A. Osuka, Angew. Chem., Int. Ed., 2015, 54, 10908.

47 S. Zakavi, R. Omidyan and S. Talebzadeh, RSC Adv., 2016, 6, 82219.

48 M. Ishida, S. Karasawa, H. Uno, F. Tani and Y. Naruta, Angew. Chem., Int. Ed., 2010, 49, 5906. 
49 M. Ishida, Y. Naruta and F. Tani, Angew. Chem., Int. Ed., 2010, 49, 91.

50 M. Ishida, S.-J. Kim, C. Preihs, K. Ohkubo, J. M. Lim, B. S. Lee, J. S. Park, V. M. Lynch, V. V. Roznyatovskiy, T. Sarma, P. K. Panda, C.-H. Lee, S. Fukuzumi, D. Kim and J. L. Sessler, Nat. Chem., 2013, 5, 15.

51 S. Fukuzumi, K. Ohkubo, M. Ishida, C. Preihs, B. Chen, W. T. Borden, D. Kim and J. L. Sessler, J. Am. Chem. Soc., 2015, 137, 9780.

52 K. E. Thomas, A. B. Alemayehu, J. Conradie, C. M. Beavers and A. Ghosh, Acc. Chem. Res., 2012, 45, 1203.

53 S. Shaik, S. Cohen, Y. Wang, H. Chen, D. Kumar and W. Thiel, Chem. Rev., 2010, 110, 949.

54 (a) E. Vogel, S. Will, A. S. Tilling, L. Neumann, J. Lex, E. Bill, A. X. Trautwein and K. Wieghardt, Angew. Chem., Int. Ed. Engl., 1994, 33, 731; (b) S. Will, J. Lex, E. Vogel, H. Schmickler, J.-P. Gisselbrecht, C. Haubtmann, M. Bernard and M. Gross, Angew. Chem., Int. Ed. Engl., 1997, 36, 357.

55 A. W. Johnson and I. T. Kay, J. Chem. Soc., 1965, 1620.

56 (a) A. W. Johnson, Pure Appl. Chem., 1971, 28, 195; (b) N. S. Hush and J. M. Dyke, J. Inorg. Nucl. Chem., 1973, 35, 4341; (c) N. S. Hush and J. M. Dyke, J. Chem. Soc., Dalton Trans., 1974, 395; (d) M. Bröring, F. Brégier, E. C. Tejero, C. Hell and M. C. Holthausen, Angew. Chem., Int. Ed., 2007, 46, 445.

57 K. Pierloot, H. Zhao and S. Vancoillie, Inorg. Chem., 2010, 49, 10316.

58 (a) K. E. Thomas, H. Vazquez-Lima, Y. Fang, Y. Song, K. J. Gagnon, C. M. Beavers, K. M. Kadish and A. Ghosh, Chem.-Eur. J., 2015, 21, 16839; (b) W. Sinha, M. G. Sommer, N. Deibel, F. Ehret, M. Bauer, B. Sarkar and S. Kar, Angew. Chem., Int. Ed., 2015, 54, 13769; (c) C. M. Lemon, M. Huynh, A. G. Maher, B. L. Anderson, E. D. Bloch, D. C. Powers and D. G. Nocera, Angew. Chem., Int. Ed., 2016, 55, 2176.

59 P. Schweyen, K. Brandhorst, R. Wicht, B. Wolfram and M. Bröring, Angew. Chem., Int. Ed., 2015, 54, 8213.

60 L. K. Frensch, K. Pröpper, M. John, S. Demeshko, C. Brückner and F. Meyer, Angew. Chem., Int. Ed., 2011, 50, 1420.

61 L. K. Blusch, K. E. Craigo, V. Martin-Diaconescu, A. B. McQuarters, E. Bill, S. Dechert, S. DeBeer, N. Lehnert and F. Meyer, J. Am. Chem. Soc., 2013, 135, 13892.

62 (a) J. H. Fuhrhop and D. Mauzerall, J. Am. Chem. Soc., 1969, 91, 4174; (b) A. Wolberg and J. Manassen, J. Am. Chem. Soc., 1970, 92, 2982; (c) C. Mangersen, J. Subramanian and J.-H. Fuhrhop, Mol. Phys., 1976, 32, 893; (d) D. Dolphin, Z. Muljiani, K. Rousseau, D. C. Borg, J. Fajer and R. H. Felton, Ann. N. Y. Acad. Sci., 1973, 206, 177.

63 W. F. Scholz, C. A. Reed, Y. J. Lee, W. R. Scheidt and G. Lang, J. Am. Chem. Soc., 1982, 104, 6791.

64 (a) A. Wolberg and J. Manassen, J. Am. Chem. Soc., 1970, 92, 2982; (b) J. T. Groves, R. C. Haushalter, M. Nakamura, T. E. Nemo and B. J. Evans, J. Am. Chem. Soc., 1981, 103,
2884; (c) P. Gans, G. Buisson, E. Duée, J.-C. Marchon, B. S. Erler, W. F. Scholz and C. A. Reed, J. Am. Chem. Soc., 1986, 108, 1223.

65 S. Thies, H. Sell, C. Bornholdt, C. Schütt, F. Köhler, F. Tuczek and R. Herges, Chem.-Eur. J., 2012, 18, 16358.

66 C. Stähler, D. Shimizu, K. Yoshida, K. Furukawa, R. Herges and A. Osuka, Chem.-Eur. J., 2017, 23, 7217.

67 M. Abe, Chem. Rev., 2013, 113, 7011.

68 Z. Zeng, X. Shi, C. Chi, J. T. L. Navarrete, J. Casado and J. Wu, Chem. Soc. Rev., 2015, 44, 6578.

69 C. Otto and E. Breitmaier, Liebigs Ann., 1991, 1347.

70 J. P. Hill, I. J. Hewitt, C. E. Anson, A. K. Powell, A. L. McCarty, P. A. Karr, M. E. Zandler and F. D'Souza, J. Org. Chem., 2004, 69, 5861.

71 I. M. Blake, A. K. Krivokapic, M. Katterle and H. L. Anderson, Chem. Commun., 2002, 1662.

72 K. Naoda, D. Shimizu, J. O. Kim, K. Furukawa, D. Kim and A. Osuka, Chem.-Eur. J., 2017, 23, 8969.

73 S. Hiroto, K. Furukawa, H. Shinokubo and A. Osuka, J. Am. Chem. Soc., 2006, 128, 12380.

74 (a) S. Ooi, T. Tanaka, K.-H. Park, D. Kim and A. Osuka, Angew. Chem., Int. Ed., 2016, 55, 6535; (b) S. Bhowmik, M. Kosa, A. Mizrahi, N. Fridman, M. Saphier, A. Stanger and Z. Gross, Inorg. Chem., 2017, 56, 2287.

75 T. Kubo, Chem. Rec., 2015, 15, 218.

76 W. Zeng, S. Lee, M. Son, M. Ishida, K. Furukawa, P. Hu, Z. Sun, D. Kim and J. Wu, Chem. Sci., 2015, 6, 2427.

77 M. Umetani, K. Naoda, T. Tanaka, S.-K. Lee, J. Oh, D. Kim and A. Osuka, Angew. Chem., Int. Ed., 2016, 55, 6305.

78 A. Tsuda and A. Osuka, Science, 2001, 293, 5527.

79 V. V. Diev, D. Femia, Q. Zhong, P. I. Djurovich, R. Haiges and M. E. Thompson, Chem. Commun., 2016, 52, 1949.

80 B. Kin, T. Yoshida, X. Li, M. Stępień, H. Shinokubo and P. J. Chmielewski, Angew. Chem., Int. Ed., 2016, 55, 13142.

81 H. Zhang, H. Plan, T. S. Herng, T. Y. Gopalakrishna, W. Zeng, J. Ding and J. Wu, Angew. Chem., Int. Ed., 2017, 56, 13484.

82 Similar hysteresis behaviors were also observed for structurally flexible diradicals, but they showed closed hysteresis loop or phase transition behavior: (a) T. Li, G. Tan, D. Shao, J. Li, Z. Zhang, Y. Song, Y. Sui, S. Chen, Y. Fang and X. Wang, J. Am. Chem. Soc., 2016, 138, 10092; (b) Y. Su, X. Wang, L. Wang, Z. Zhang, X. Wang, Y. Song and P. P. Power, Chem. Sci., 2016, 7, 6514.

83 Y. Jun-i, N. Fukui, K. Furukawa and A. Osuka, DOI: 10.1002/ chem.201705769.

84 T. Y. Gopalakrishna, J. S. Reddy and V. G. Anand, Angew. Chem., Int. Ed., 2014, 53, 10984.

85 W.-Y. Cha, T. Kim, A. Ghosh, Z. Zhang, X.-S. Ke, R. Ali, V. M. Lynch, J. Jung, W. Kim, S. Lee, S. Fukuzumi, J. S. Park, J. L. Sessler, T. K. Chandrashekar and D. Kim, Nat. Chem., 2017, 9, 1243.

86 E. Iwamoto, K. Hirai and H. Tomioka, J. Am. Chem. Soc., 2003, 125, 14664.

87 F. Dielmann, O. Back, M. Henry-Ellinger, P. Jerabek, G. Frenking and G. Bertrand, Science, 2012, 337, 1526. 